\title{
LA LITURGIA PROCESIONAL DE COMPLETAS EN EL ÁMBITO DE LOS MONASTERIOS FEMENINOS DE LA ORDEN DE PREDICADORES EN CASTILLA
}

\author{
POR \\ MERCEDES PÉREZ VIDAL ${ }^{1}$ \\ Università degli Studi di Padova
}

\begin{abstract}
RESUMEN
La liturgia de las monjas dominicas castellanas y, por extensión, la de los monasterios femeninos en la Península lbérica, ha sido escasamente estudiada y sigue siendo un asunto prácticamente desconocido. En consecuencia, el estudio del arte y la arquitectura en relación a la liturgia no ha tenido apenas impacto en la historiografía del monacato femenino en este ámbito. En este artículo se analizan los problemas de tal metodología en el estudio de los monasterios de dominicas de la Provincia de España, destacando la necesidad de adoptar un enfoque integrador, que tenga en consideración los escasos libros conservados, junto a otro tipo de fuentes documentales y también los edificios en sí mismos. Posteriormente, siguiendo esta metodología, se intenta reconstruir la celebración de la compleja liturgia de completas y el uso de los espacios monásticos a tal fin en estas fundaciones. Finalmente, se analizan los espacios destinados a la penitencia y también la probable influencia de ciertos movimientos ultrarrigoristas en tales prácticas y en la construcción de estos edificios.
\end{abstract}

PALABRAS ClaVE: liturgia y arquitectura; monjas dominicas; estudios de la mujer; completas.

\section{LITURGY OF COMPLINE AND ITS PROCESSIONS IN THE CONTEXT OF DOMINICAN CASTILIAN NUNNERIES}

\begin{abstract}
The liturgy of Dominican nuns in Castile and, by extension, the liturgy within nunneries in the Iberian Peninsula, has been scarcely researched and it remains almost unknown. As a consequence, the study of art and architecture in relation to liturgy has made little impact in the historiography of women's monasticism in this area. In this article we discuss the issues of the application of this methodology in the research of the Dominican nunneries of the Province of Spain, stressing the necessity of adopting an integrating approach, which takes into account the rare liturgical books surviving, together with other documentary sources and also the buildings themselves. Then, following this methodology, we try to reconstruct the performance of the complex liturgy of Compline and the use of monastic spaces with this purpose within these nunneries. Finally, we also discuss the spaces for doing penance and the likely influence of some ultra-rigorist movements both on those practices and on the construction of these buildings.
\end{abstract}

KEY WORDS: liturgy and architecture; Dominican nuns; women's studies; compline.

Cómo CITAR ESTE ARTículo / CITATION: Pérez Vidal, M. (2017). «La liturgia procesional de completas en el ámbito de los monasterios femeninos de la Orden de Predicadores en Castilla» Hispania Sacra 69, 139: 81-99 doi: 10.3989/hs.2017.06

$\begin{array}{ll}\text { Recibido/Received } & 22-02-2013 \\ \text { Aceptado/Accepted } & 14-06-2014\end{array}$

Pese a su ya dilatada trayectoria y a la abundancia de publicaciones y reuniones científicas, el llamado "giro litúrgico» en el estudio del arte y la arquitectura apenas ha tenido incidencia en el estudio del monacato femenino hispano. Dejando a un lado otras razones, la causa principal de que tal metodología haya permanecido prácticamente inexplorada en este ámbito hasta el presente, ha sido

\footnotetext{
1 mercedespvidal@gmail.com / ORCID iD: http://orcid.org/0000-
} 0002-0573-0681 sin duda el desconocimiento de una liturgia creada por y para las mujeres. Tal situación es consecuencia de la prácticamente nula incidencia de los estudios feministas en la historiografía sobre la liturgia hasta la década de los noventa del siglo pasado, situación que, en el caso hispano, se ha prolongado hasta la actualidad. ${ }^{2}$

2 Una síntesis de los avances hasta entonces fueron recogidos en un volumen editado conjuntamente por Berger y Gerhards (eds.) 1990. Véase también una publicación más reciente de la primera: Berger 2011. 
No obstante, esta invisibilidad de las mujeres y la asignación de un papel pasivo a las mismas por parte de los historiadores de la liturgia tiene un origen muy anterior, hundiendo sus raíces, en última instancia, en los siglos bajomedievales, cuando diversos concilios y tratados de derecho canónico -como el Decretum Gratiani-insistieron en limitar su participación, reduciéndolas a meras espectadoras, alejándolas especialmente de la celebración y administración de la Eucaristía. ${ }^{3}$ Esta postura tuvo su materialización física en el espacio sacro, con las separaciones existentes en el interior de los templos, algo en lo que insistieron especialmente los reformadores, a fin de mantener el decoro en la celebración litúrgica. ${ }^{4}$

Lógicamente, el despegue, aunque tímido, de una historiografía feminista de la liturgia en otros ámbitos geográficos ha auspiciado la proliferación de estudios sobre el papel de las mujeres en la liturgia y su relación con el arte y los espacios arquitectónicos. En este sentido, cabe destacar los trabajos de Gisela Muschiol y, especialmente, por su relación con los asuntos tratados en este artículo, los de Carola Jäggi sobre monasterios de clarisas y dominicas. ${ }^{5}$

HACIA UNA DEFINICIÓN DE UNA LITURGIA PROPIA DE LAS MONJAS DOMINICAS. FUENTES PARA SU ESTUDIO

Centrándonos en la liturgia de estas últimas, el principal problema que encontramos es la falta de referencias a la misma tanto en las Constituciones como en las Actas de los Capítulos Generales y Provinciales. Esto, unido a la obligatoriedad de la práctica litúrgica establecida por los frailes para toda la Orden, ha llevado a suponer que la liturgia de las monjas habría sido un mero trasunto de la de aquellos, sin personalidad propia.

La Orden de Predicadores desarrolló un rito propio desde sus orígenes que, debido al origen de su fundador, se vertebró sobre el modelo canonical, aunque acusando el influjo de las iglesias locales, dando lugar enseguida a diferencias entre las distintas provincias, contra las cuales la Orden luchó sistemáticamente. Ya en las Constituciones de los frailes elaboradas por Raimundo de Peñafort en 1241 se prescribió el uso de los mismos textos litúrgicos en todas partes, aunque tal disposición no debió tener efecto pues en años sucesivos se adoptaron nuevas medidas a fin de conseguir la ansiada uniformidad de la liturgia dominica. ${ }^{6}$ En 1245 se nombró una comisión de cuatro frailes, en representación de las provincias de Francia, Inglaterra, Lombardía y Teutonia, que debían revisar los textos exis-

3 Frente a la demostrada existencia de mujeres ordenadas en los primeros siglos del Cristianismo, a partir del IX actas conciliares y tratados impidieron a las mujeres la administración de la comunión e incluso tocar los vasos sagrados o las vestiduras, algo que fue reiterado en los tratados y decretos del siglo XIII. En el De Consecratione, inserto en la segunda parte del Decretum Gratiani, se prohibía a las mujeres administrar el sacramento a los enfermos y bautizar, excepto en casos de necesidad (Macy 2000 y 2008; Clark 2002).

4 Savonarola reiteró en sus sermones la incomodidad que suponía la presencia de las mujeres en el templo (Zanovello 2009).

5 Muschiol 1994, 2001, 2003, 2008, 2010, 2012 y 2013; Jäggi 2000, 2001, 2002 y 2006; Jäggi y Lobbedey 2008.

6 Creytens 1948: nota 31. En lo que respecta a los libros anteriores a 1254, véase Gleenson 1972; Dirks 1979 y Gleenson 2004. tentes en éstas a fin de establecer un modelo único. Los resultados de dicha comisión fueron modificados de nuevo en el capítulo de Metz de 1251, aunque tampoco esta tercera corrección fue satisfactoria. Finalmente, el Capítulo general de Buda de 1254 confió a Humberto de Romans, recién elegido Maestro general de la Orden, una nueva revisión del Oficio eclesiástico y de los libros litúrgicos. El resultado de la corrección de Romans fue el Ecclesiasticum officium (aprobado en el capítulo general de París de 1256 y confirmado por Clemente IV en 1267) que constituye un corpus de catorce libros, conservados en el llamado códice "Prototipo», en el Archivo General de la Orden de Predicadores en Santa Sabina (Roma). ${ }^{7}$

Mientras que la Iglesia de Roma evolucionó en los siglos sucesivos hacia formas nuevas, la liturgia dominica se mantuvo bastante apegada a su modelo establecido a mediados del siglo XIII, permaneciendo sin cambios sustanciales hasta el Concilio Vaticano 1 I. ${ }^{8}$ En los sucesivos capítulos generales y provinciales, y especialmente durante la reforma, se insistió en la uniformidad que debía existir dentro de la Orden y en la necesidad de atenerse a lo contenido en el "Prototipo", prohibiéndose la introducción de modificaciones en el texto y la música. ${ }^{9}$ Se prescribía además que, antes de ser utilizado, cada libro fuese certificado, esto es, que no sólo era escrito siguiendo el método dominico medieval de dibujar los neumas usando una plantilla estandarizada, sino que la música contenida en él debía ser cantada por dos frailes o monjas usando el «nuevo» libro contra otros dos frailes o monjas usando

7 AGOP, Serie XV, Ms. XVI, L1. Este códice, procedente del convento de Saint-Jacques de París, fue digitalizado en Berlín en 2002. Contiene los catorce libros de la liturgia dominica: ordinario, martirologio, colectario, procesionario, salterio, breviario portátil, leccionario, antifonario, gradual, pulpitario, misal conventual, epistolario, evangeliario y misal de los altares menores. En 1999 se celebró en Roma una conferencia sobre el mismo: Boyle y Gy (dirs.) 2004. Del Prototipo se realizaron diversas copias para uso de las demás provincias, una de las cuales se conserva en el convento de San Esteban de Salamanca. Esta contiene cuatro de los catorce libros del prototipo humbertino, a saber: antifonario, pulpitario, gradual y procesionario (Fueyo Suárez 2007, reed. en 2012).

8 No obstante, a pesar de que el Ecclesiasticum Officium de Romans continuó en uso, tras el Concilio de Trento estos libros se habían vuelto un instrumento inadecuado y los capítulos generales crearon sucesivas comisiones para la redacción de un Ceremonial. Sin embargo, esto no se pudo llevar a cabo hasta 1868, año en que fue promulgado el Caeremoniale iuxta ritum Sacri Ordinis Praedicatorum por el maestro general Jandel, el cual permaneció en uso hasta el Capítulo General de River Forest de 1968. En este último se aprobaron las Constituciones reelaboradas según las determinaciones del Concilio Vaticano II, decretándose la adopción del rito romano renovado por parte de la Orden. Finalmente, en el capítulo general de Madonna dell'Arco de 1974 fueron aprobadas las Indicationes pro celebrationibus liturgicis in Ordine Fratrum Praedicatorum, que pretendían preservar algunas de las características propias del rito dominico (Gilardi 2006: 52).

9 Por ejemplo, en el Capítulo de Salamanca de 1489 se decía: "queremos que, en el mismo oficio divino como en las demás cosas que se hayan de leer o cantar, se observe la uniformidad en todos los conventos de la Congregación. Esto se efectuará sin duda, si todos leen y cantan no según su capricho sino conforme a lo escrito en los libros», Acta del Capítulo de la Congregación de la Observancia celebrado en Salamanca en 1489, 4.1 y también «queremos y ordenamos que todas las solemnidades en nuestros conventos se hagan uniformemente, según lo que se contiene en el Calendario y en el Ordinario», Ibídem, 4.4 en Hernández Martín 1980: 50. 
un libro más antiguo «certificado» o «acreditado». Esto aseguraba que todos los libros de canto dominicos eran absolutamente idénticos. ${ }^{10}$

Sin embargo, la uniformitas diu desiderata de la liturgia dominica no fue aplicada de forma rígida, sino que se conjugó ya desde el inicio con una cierta flexibilidad. Como indicó el propio Humberto de Romans, debido a que los Predicadores contaron con conventos en contextos muy distintos y a los continuos viajes y ausencias de los mismos, la total uniformidad constituía ciertamente una utopía. ${ }^{11}$ Por ello, tanto en el ordinario, como en el misal, en leccionarios y en algunas partes de los breviarios portátiles pervivieron las diferencias regionales y locales. ${ }^{12}$ Son precisamente estos libros los que nos permiten conocer las peculiaridades de la liturgia desarrollada en cada convento. De igual forma, pese a la ausencia de referencias en las actas conciliares y documentación oficial, es posible conocer la liturgia de las monjas a través del estudio de los libros litúrgicos procedentes de sus monasterios. Sin embargo, lamentablemente, hasta la fecha apenas se ha transitado esta vía de investigación. Además de a la ya señalada visión androcéntrica de los estudios de la liturgia, las causas de tal olvido han sido la dificultad que presenta la consulta de estos códices cuando aún se conservan en los monasterios, la inexistencia en la mayoría de los casos de un catálogo exhaustivo de los libros conservados, y sobre todo, la desaparición o dispersión de la mayoría de los ejemplares de cronología medieval. ${ }^{13}$

Tal pérdida no debe achacarse en su totalidad a la incuria de tiempos recientes sino que tuvo lugar, en gran medida, entre los siglos XV y XVI, a consecuencia de la introducción de la observancia. Los libros anteriores, al no adecuarse al nuevo rito reformado, y a los numerosos cambios introducidos en el calendario, perdieron su valor funcional y debieron rehacerse. Así sucedió en el monasterio dominico de Nossa Senhora do Paraíso de Évora, del que se conservan el Livro da Regra e Constituiçoes, así como varios libros de coro, en la Biblioteca Nacional de Portugal, todos ellos posteriores a la introducción de la reforma. ${ }^{14}$ A esto cabe sumar el proceso de revisión y reforma de los libros litúrgicos acometida en la Orden de Predicadores en la primera mitad del siglo XVı y especialmente a raíz del capítulo general de Salamanca de 1551.

\footnotetext{
10 Huglo 1967.

11 Tugwell 1993; Gilardi 2004: 381.

12 Así, tanto en las rúbricas del Ordinario como en las existen-
} tes en el resto de los libros litúrgicos pueden leerse indicaciones que evidencian que se tenían en cuenta los distintos usos locales, las dimensiones del convento y el variable número de frailes: «in parvis conventibus», o "si vero Conventus adeo magnus fuerit», o "Acolythi autem infra gradus Presbyterii vel in primis sedibus Chori, maxime ubi pauci sunt Fratres, stent parati ad sua ministeria peragenda», Guerrini (ed.) 1921, cit. en Gilardi 2004: 385

${ }_{13}$ En el caso hispano, esta escasez de ejemplares medievales no se limita a las fundaciones femeninas, sino que fue también característica de los conventos masculinos. Casi la totalidad del centenar de libros litúrgicos conservados en San Esteban de Salamanca, de variada procedencia, es posterior al siglo xVI. Un catálogo de los cantorales en Calvo Alonso 2011. Quiero agradecer especialmente a Iván Calvo Alonso sus apuntes y sugerencias sobre la liturgia de completas, y su inestimable ayuda no solo en este caso, sino en toda mi investigación sobre la Orden de Predicadores.

14 Frazão 1998.
Otro factor de suma importancia fue la invención de la imprenta, que ocasionó la devaluación de todos los códices manuscritos, cuya letra gótica y abreviaturas los hizo cada vez más ilegibles, y que fueron arrinconados, perdiéndose y dispersándose buena parte de ellos. ${ }^{15}$ De igual forma, los libros litúrgicos sin notación musical perdieron rápidamente su valor, al no adecuarse al nuevo ordinario, y fueron destruidos o abandonados en muchos casos, siendo sustituidos por ejemplares impresos. En cambio, dado el elevado coste que suponía imprimir los libros con notación musical, estos siguieron produciéndose de forma manuscrita a lo largo del siglo xvi y, en menor medida, en las centurias sucesivas. ${ }^{16}$

FIGURA 1

Breviarium Portatile de Santo Domingo el Real de Toledo, AMSDRT, Final. Ca. 1460-1470. Letanía y commendatio animarum. (Foto: M. Pérez Vidal)

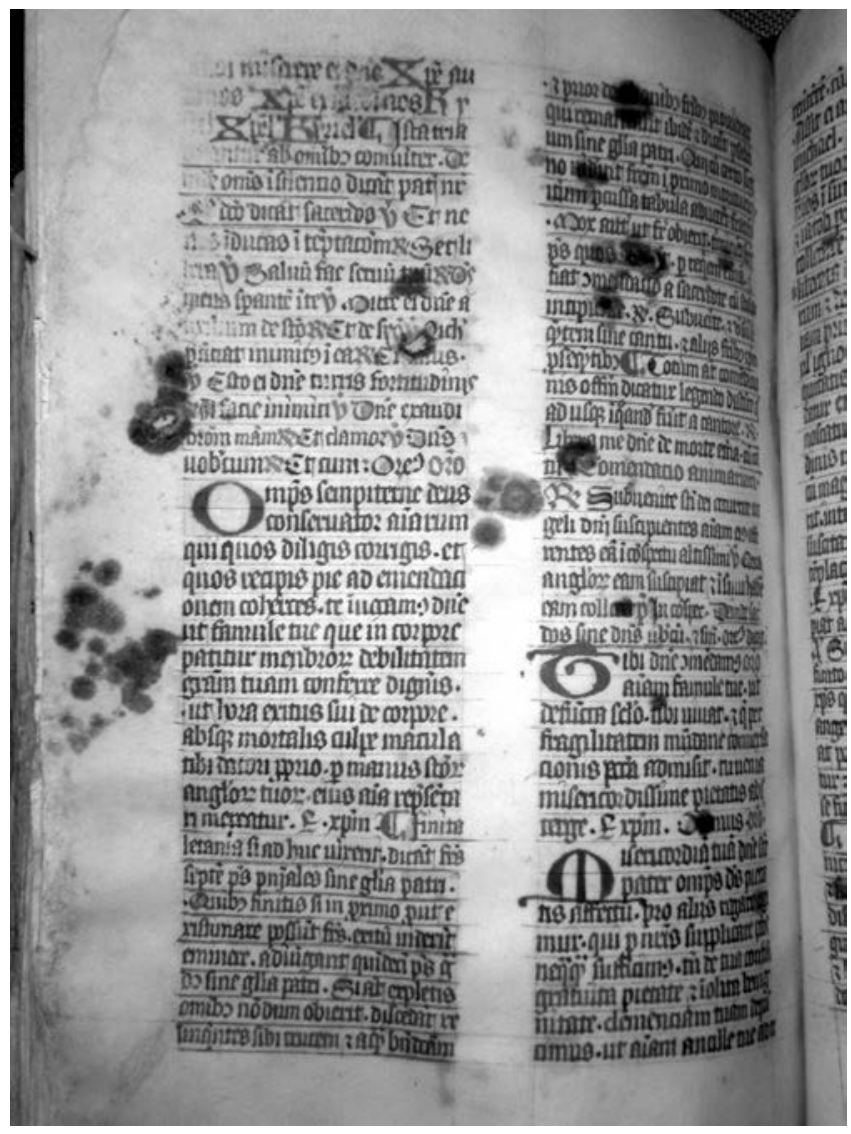

15 Una buena colección de estos antiguos manuscritos, datados entre los siglos XIII y xv, y procedentes de diversos conventos de Castilla, Aragón, Valencia y Cataluña, fueron reunidos por Torquemada y por sus sucesores ya en el siglo XVI, en el convento abulense de Santo Tomás, pasando en el siglo XVIII a la Biblioteca Nacional, gracias a una permuta realizada entre esta institución y el convento. Esta rica biblioteca estuvo destinada al estudio y consulta por parte de los profesores y alumnos del Estudio General, y posterior universidad de Santo Tomás. En consecuencia, se trató en su mayor parte de códices de teología, medicina, derecho, gramática y filosofía. No encontramos manuscritos litúrgicos, con excepción, curiosamente, de un breviario franciscano. Breviarium Fratrum Minorum secondum consuetudinem Romanae Curiae, saec. 14. Andrés 1989: 118.

16 Fueyo Suárez 2008: 182. 
Los dominicos fueron además pioneros en la utilización del nuevo invento, instalando rápidamente imprentas en sus conventos, y también en los monasterios femeninos, como fue el caso de San Jacopo di Ripoli. ${ }^{17}$ En consecuencia, los libros litúrgicos dominicos fueron dados rápidamente a la prensa. De 1476 data la primera impresión del breviario en Milán, mientras que el misal dominico fue editado por primera vez en Venecia en 1482 y al año siguiente, en esta misma ciudad, el diurnal. Este recibió otras dos ediciones en 1484 en Venecia y Nápoles. ${ }^{18}$ El único libro con notación musical que fue impreso masivamente, a pesar de los elevados costes que esto suponía, fue el procesionario, que en España se editó al menos seis veces entre 1494 y 1609. ${ }^{19}$

El monasterio toledano de Santo Domingo el Real ilustra perfectamente este problema, pues los libros sin notación que han llegado hasta nosotros son, salvo uno, posteriores al capítulo de Salamanca y, por lo tanto, reformados y revisados. Además de estos libros manuscritos se conservan otros impresos, adaptados al nuevo rito, como se indica expresamente en un diurnal, cuya realización se ha situado entre 1558 y 1560 . Junto a este destacan un ordinario, realizado en 1574, y un martirologio de 1579. Sin embargo, aún estos libros reformados parecen haber quedado en desuso, como prueba que el citado diurnal fuese hallado en el curso de unas obras para hacer el nuevo cementerio. ${ }^{20}$

Similar fue el hallazgo de un libro aun más interesante, también en este monasterio toledano. Se trata de un Breviarium Portatile encontrado en 1993 inserto en el hueco de una pared del noviciado, que parece haber sido horadado ex profeso para albergar el códice. Este constituye una reliquia, un unicum, pues no hemos conservado libros de este tipo en ninguno de los monasterios femeninos de la Orden en España. Se trata también en este caso de un libro sin notación, destinado al uso personal de una religiosa y no a su uso coral, y presenta tres partes distintas, realizadas entre los siglos XIV y XV, que fueron posteriormente unidas en un solo volumen. ${ }^{21}$ De ellas, resulta especialmente interesante la tercera, compuesta en Toledo entre 1460 y 1470 para el propio monasterio de Santo Domingo el Real o por encargo suyo, tal y como evidencian la aparición de festividades de la iglesia toledana y el uso del femenino en las rúbricas -aunque no de forma sistemática-, así como la representación del mismo anagrama que encontramos en

17 El cardenal dominico, Juan de Torquemada impulsó el establecimiento de una imprenta en la abadía de Subiaco, de la cual era abad in commendam, en 1464. En 1476 los dominicos fueron también los responsables del establecimiento de la imprenta en Florencia, en San Jacopo di Ripoli. No muchos años después, en 1483, se instaló una imprenta similar en el convento toledano de San Pedro Mártir (Barrado Barquilla 1985).

18 Bonniwell 1945: 270.

19 Fueyo Suárez, B. 2008: 182 y 2011 (reed. en 2012).

20 Galán Vera 2007: 79.

21 La parte central, la más antigua, fue realizada a comienzos del siglo XIV, e incluye algunas rúbricas en francés en el salterio, mientras que el resto recoge oficios y memorias de varios santos ingleses. La segunda parte, de origen zamorano, fue realizada en 1382, mientras que la tercera fue elaborada en Toledo entre 1460 y 1470. En la Orden de Predicadores, el Breviario no tuvo uso coral hasta y avanzado el siglo XVIII. AMSDRT, Ms 06/508. Fueyo Suárez 2009a y 2009 b. diversos objetos y partes del conjunto monástico. ${ }^{22}$ Este libro debió ser ocultado en esta cavidad a consecuencia de la reforma, dado que los breviarios, y particularmente aquellos manuscritos, fueron considerados objetos de lujo por muchos reformadores. ${ }^{23}$

Aparte de este ejemplar, en la rica biblioteca del monasterio toledano encontramos sobre todo numerosos libros de coro, antifonarios e himnarios, es decir, aquellos libros que no fueron sustituidos con la llegada de la imprenta por la dificultad que entrañaba su reproducción. No obstante, aún en este caso, únicamente se conservan cuatro antifonarios anteriores al siglo XVI, realizados en la segunda mitad del siglo XV: uno perteneciente al tiempo Pascual, otro al Adviento, un antifonario que contiene la misa de la Resurrección hasta el domingo de la Santísima Trinidad, y un antifonario de oficios litúrgicos, sin más especificación. ${ }^{24}$ Prácticamente todos ellos recogen música monódica, con la excepción de una serie de hojas sueltas con fabordones que fueron realizados entre la segunda mitad del $x V$ y el siglo xIX. ${ }^{25}$

22 En contra de lo señalado por Fueyo, el uso del femenino no es exhaustivo, sino que se alterna con el masculino, evidenciando el descuido o falta de celo por parte del o la copista, que se basó claramente en un libro compuesto para los frailes. Estos errores de género en manuscritos copiados para o por las monjas fueron habituales. Se encuentran también, por ejemplo en el códice RAH 75, procedente de San Pedro de Cardeña y que contiene la Diadema monachorum de Smaragdus. Datado en un principio en XIV, tales equívocos hicieron suponer a Ghislain Baury que dicho códice habría sido copiado por los monjes de Cardeña a partir de otro perteneciente a las cistercienses de Cañas. Sin embargo, Ana Suárez González ha adelantado su fecha de realización, considerando que, en realidad, podría tratarse del original escrito para las monjas a finales del XII, sin que sepamos cómo fue a parar a Cardeña (Baury 2010). Agradezco al Dr. Baury las últimas novedades sobre la datación del códice, así como otras informaciones que ha tenido la generosidad de confiarme.

23 En una carta enviada a Maddalena Picco della Mirandola en 1495, Savonarola describía el breviario personal como una traición al voto de pobreza de la religiosa, e instaba a las monjas a usar breviarios impresos y de posesión común o, mejor aún, a no utilizar breviarios en absoluto (Roberts 2008: 26).

24 Un catálogo de estos libros puede verse en Galán Vera, Martínez Gil y Peñas Serrano 2005: 279-293. Los citados antifonarios del siglo XV corresponden a los números 16, 17, 18 y 19 del mismo.

25 Las dominicas toledanas -siguiendo la práctica habitual en las iglesias y conventos españoles durante los siglos XVI y XVII- alternaron el canto llano, con la polifonía a facistol y las partes instrumentales, bien con órgano o con un conjunto de ministriles. Así lo prueba la inserción de estos cuatro fabordones en un códice misceláneo de canto en el que se recogían las festividades de Santa Catalina de Siena, Santa María Magdalena, Santo Domingo y Santo Tomás de Aquino. Aunque estas piezas fueron escritas en el siglo XVII, como ha señalado Martínez Gil, el arcaísmo de su notación evidencia que se trata probablemente de una copia de otras pertenecientes a un repertorio practicado anteriormente, y probablemente recogidas en un libro de de ministriles, de los siglos XV o XVI. A pesar de la depuración impuesta por Trento a las prácticas musicales, los fabordones también fueron permitidos por tratarse de una polifonía muy simple, una mera armonización de la melodía del canto llano y por la inteligibilidad del texto. Estas piezas serían interpretadas por el grupo de monjas cantoras e instrumentistas existentes en el monasterio (Galán Vera, Martínez Gil y Peñas Serrano 2005: 300-304). 
FIGURA 2

Forma y manera de cómo las monjas del orden de Sancto Domingo de los Predicadores han de hacer profesión a su priora (ritual de profesión). AMSDRS. (Foto: M. Pérez Vidal)

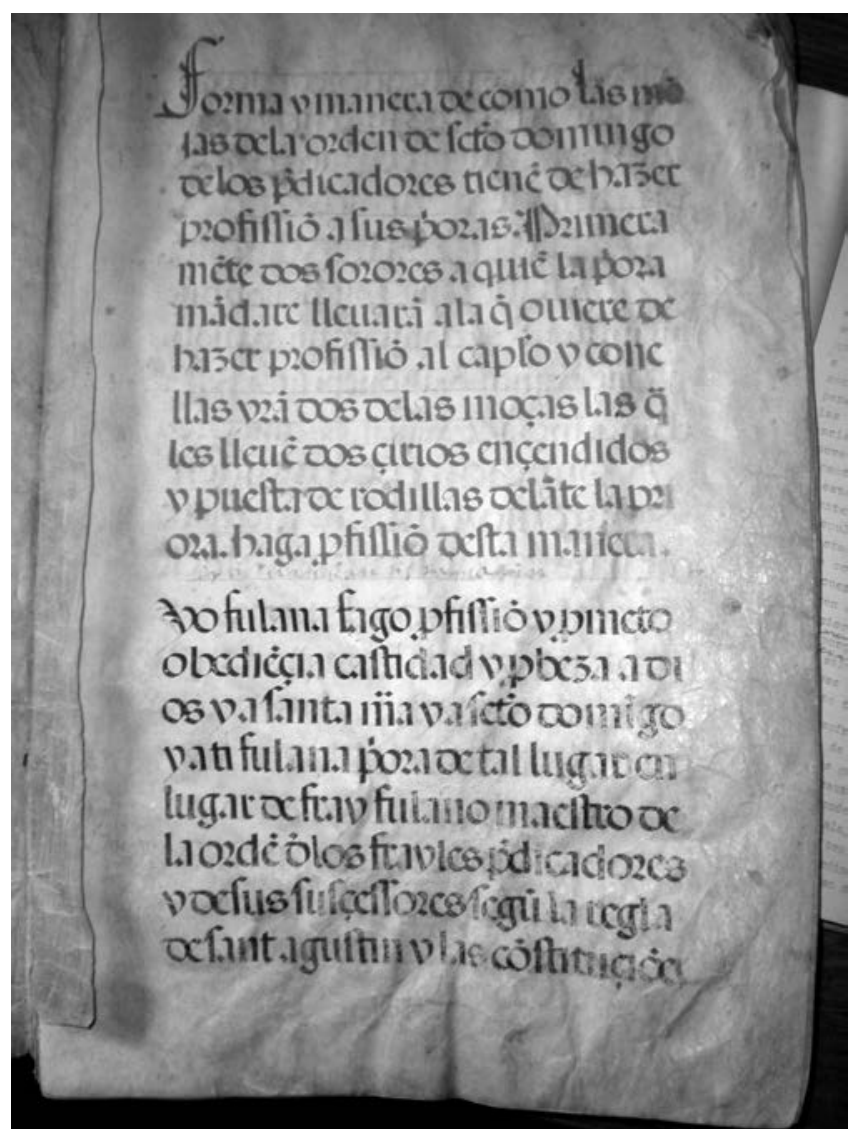

No obstante, el corpus de libros de coro toledanos, a pesar de estas ausencias, no deja de ser un caso excepcional en el pobre panorama del resto de los monasterios castellanos. ${ }^{26}$ Aparte de Toledo, únicamente los monasterios de Zamora y Segovia han conservado alguna reliquia de este pasado litúrgico. En el primero se conserva un cantoral, muy tardío, que puede datarse en el siglo XVIII pues en él aparece el oficio del Santo Nombre de Jesús. ${ }^{27}$ Por su parte,

26 En el archivo de Santo Domingo el Real de Toledo se conservan también algunos libros procedentes del monasterio de las dominicas de Jesús y María y del convento de San Pedro Mártir.

27 Aunque el culto al Dulce Nombre de Jesús se remonta al generalato de Juan de Vercelli (1264-1283) y a partir de 1430 se documenta la existencia de cofradías dedicadas al mismo en España, siendo la primera la establecida por fray Diego de Vitoria en el convento de San Pablo de Burgos, el oficio es posterior. Pío V confirmó estas cofradías en 1571 confiándoselas a los dominicos. Aunque tal festividad no fue establecida universalmente para toda la iglesia hasta 1721 , ya había sido incorporada al calendario dominico en la centuria anterior, en la revisión de los libros litúrgicos debida al maestro general Antonio Cloche, fijándose el 15 de enero. No obstante, el papa Inocencio XIII la estableció en el domingo comprendido entre la Circuncisión y la Epifanía, o en su defecto, el día 2 de enero (Bonniwell 1945: $344-$ 346). En consecuencia, pese a su tardía incorporación al oficio, dada la documentada existencia de cofradías previas, tal festividad puede aparecer en algunos libros de uso privado, como, por ejemplo, en el mencionado diurnal toledano. No obstante, en este caso se trata de una adición posterior y no pertenece al oficio dominico. en Santo Domingo el Real de Segovia se conserva un ritual de profesión, manuscrito, datado probablemente en el segundo cuarto del siglo XVI y escrito en romance, al que posteriormente se le añadieron unos folios con notación musical monódica. ${ }^{28}$ En un primer momento, este tipo de rituales no constituyeron un libro independiente sino que formaron parte de los procesionarios. Como resulta lógico, estos últimos son los que mejor permiten conocer el desarrollo de la liturgia procesional en los monasterios, aportando además precisas indicaciones topográficas en sus rúbricas, al hacer referencia a los altares y estaciones litúrgicas. Resulta llamativo que, a pesar de la documentada existencia de este tipo de libros litúrgicos en los conventos masculinos desde el siglo XIII en adelante, casi todos los conservados procedan de monasterios femeninos. ${ }^{29} \mathrm{Se}$ trató de pequeños libros, hechos para la maestra de canto, o capíscola, pero también para el resto de las monjas participantes en las procesiones. En ellos se contienen los oficios para determinadas festividades, y una importante parte de los mismos estuvo dedicada a la liturgia de difuntos. ${ }^{30}$

Lamentablemente, el caso ibérico no es parangonable a la riqueza de algunos monasterios dominicos extranjeros, en los cuales ocuparon un papel destacado este tipo de libros. Este fue el caso de San Luis de Poissy, del que procede un abundante corpus de libros litúrgicos, con y sin notación musical, actualmente dispersos en diversas bibliotecas y colecciones privadas, en el que se encuentran, entre otros, un total de treinta y un procesionarios, cuya evolución desde el siglo XIV hasta 1540 aproximadamente ha sido estudiada por Naughton. ${ }^{31}$ Del mismo modo, cabe destacar el ceremonial y el procesionario del monasterio de Oetenbach, que datan del siglo xIV y proporcionan una inestimable información sobre la celebración litúrgica en este. ${ }^{32}$ Así como los pertenecientes a las dominicas de Estrasburgo y conservados en la Badische Landesbibliothek de Karlsruhe; ${ }^{33}$ o los procedentes del monasterio de Unterliden, en Colmar, que permiten reconstruir con gran precisión la liturgia de este monasterio alsaciano. ${ }^{34}$

El resto de los libros $-y$ especialmente aquellos sin notación musical- desaparecieron e incluso las noticias acerca de los mismos son muy escasas. Entre las pocas conocidas se encuentra la que nos proporciona una carta de comienzos del xV conservada también en el archivo de Santo Domingo el Real de Toledo. Por ella, la reina Leonor

28 AMSDRS, Forma y manera de cómo las monjas del orden de Sancto Domingo de los Predicadores han de hacer profesión a sus prioras, s/f. Otro ritual de profesión, datado en 1571, se conserva en el archivo del convento dominico de Santa María del Castello, procedente del extinto monasterio dominico de San Giacomo e Filippo (Badano 2010). Este tipo de rituales para el uso de los dominicos, y especialmente aquellos escritos en lengua vernácula, parecen haber sido una rareza (Thomas 1969).

29 Hamburger 2000.

30 Sobre las partes integrantes del procesionario dominico véase «Tableau VII. Le Processional Dominicain», en Huglo 1999: 53-54.

31 Huglo 1990; Naughton 1998 y 1999-2000.

32 Wehrli-Johns. $\mathrm{M}$ and Wolfram Schneider-Lastin. W. 1999. «Zürich ZH, Oetenbach, Dominikanerinnen». Helvetia Sacra IV/5: 1019-1053, cit. en Jäggi 2000: 101

33 BLB. St. Prozessionale, Rituale, St. Peter perg. 21; y Prozessionale, St. Peter perg. 22

34 Hamburger 2000: 123. 
de Alburquerque solicitaba a su prima, María de Castilla, priora del monasterio toledano, un ordinario escrito en romance, a fin de que le hiciesen una copia del mismo. ${ }^{35}$ Tal copia bien pudo haber estado destinada, a mi juicio, a Santa María la Real de Medina del Campo, otro monasterio de dominicas, al cual la reina donó en 1418 sus palacios anejos. ${ }^{36}$ Asimismo, no debe descartarse que las copistas fuesen las propias monjas de Medina, o de Toledo, teniendo en cuenta que los dominicos de San Pedro Mártir carecían de un scriptorium y que el trabajo de las monjas como copistas y miniaturistas no fue extraño. ${ }^{37}$ Pese a que tal actividad había sido prohibida por el capítulo general de Tréveris de 1249 fue posteriormente alentada por algunos reformadores como Giovanni Dominici y Savonarola. ${ }^{38}$ En consecuencia, los monasterios observantes italianos contaron frecuentemente con un scriptorium, como fue el caso de San Domenico di Pisa, San Domenico di Lucca o del ya mencionado San Jacopo di Ripoli, en el que, como se ha visto, se estableció además una de las primeras imprentas florentinas. $^{39}$ De igual forma, los reformadores de la

35 AMSDRT, Doc. n. 117. La carta ha sido datada entre 1416 y 1424 (Fueyo Suárez 2008: 184).

36 Santa María la Real de Medina del Campo tuvo su origen en un monasterio premostratense, que había pasado en 1402 a la Orden de Predicadores, con la aprobación de Benedicto XIII. En 1418 la reina donó sus palacios adyacentes para la ampliación de su edificio (López [1613] 2003: f. 28; Rodríguez y Fernández 1903: 529).

37 Tanto en Italia como en Alemania se han dedicado en los últimos años numerosos estudios a la producción de manuscritos, y también de libros impresos, para y por las comunidades religiosas femeninas. As pues, no solo conocemos los nombres de numerosas prioras y monjas que encargaron tales manuscritos, sino también los de algunas monjas copistas e iluminadoras, como Sor Eufrasia Burlamacchi, monja en Santo Domingo de Lucca, directamente bajo la influencia de Savonarola, Sor Domenica da Recarco da Verona, monja en San Vincenzo de Mantua, o Barbara Gewichtmacherin, quien fue enviada de Gebweiler a Santa Catalina de Núremberg, donde dio comienzo a una suerte de escuela de monjas iluminadoras (Tozzi 2011; Carroll 2012; Sauer 2007). Asimismo, aunque no han merecido la misma atención por parte de los historiadores, y se trata de ejemplos bastante tardíos, conocemos algunas monjas dominicas que copiaron libros en Portugal en la primera mitad del XVI, como una tal «soror Antonia»; que copió un Antiphonarium Temporale en 1528 y otro Sanctorale en 1551, ambos para el monasterio de Nossa Senhora da Anunciada en Lisboa, por orden de la priora doña Britiz de Menezes (Alvarenga 1992).

38 El capítulo general de Tréveris había establecido que «Fratres non faciant sibi scribi psalteria vel alia scripta per moniales, vel alias mulieres», en Acta capituli generalis apud Treverim celebrati anno Domini MCCXLX, MOPH 3(1220-1303), Constitutiones et Acta Ordinis Fratrum Praedicatorum: 1232-2001: 47. Digitale Bibliothek Spezial. Berlin: Direcmedia Publishing y Istituto Storico Domenicano, 2002.

39 Noakes 1991; Conway 1999. Las monjas de San Jacopo a Ripoli trabajaron a veces como tipógrafos, pero la cuantiosa producción impresa se debió en su mayor parte a personal masculino, tanto frailes como laicos. En fechas más tardías, entre 1557 y 1561, existió también una imprenta en una fundación veneciana de monjas agustinas. Quiero agradecer a Melissa Moreton (2013) su gentileza al proporcionarme estas informaciones que forman parte de su tesis doctoral. En España, una de las primeras imprentas fue la establecida en el convento de San Pedro Mártir de Toledo, pero no parece haber constancia de la existencia de ninguna en fundaciones femeninas. Véase al respecto lo referido en la nota 17 . No obstante, cabe tener presente de nuevo la ausencia de un enfoque de género en el estudio de estas cuestiones en el ámbito ibérico y la escasa atención prestada al trabajo de las monjas no solo miniaturistas, sino también como pintoras, bordadoras, etc. Como se ha visto, en otros ámbitos geográficos, como el germano, tal olvido únicamente ha comenzado a superarse a partir de la década de los noventa (Hamburger 1997). provincia de Teutonia también alentaron a las monjas en la copia e iluminación de manuscritos, como prueba el notorio ejemplo del scriptorium de Santa Catalina de Núremberg. ${ }^{40}$

Los ejemplos referidos evidencian el papel activo que tuvieron las mujeres, tanto las fundadoras como las propias monjas, en la configuración de la liturgia, no solo como copistas, sino también a través de la transmisión de manuscritos de unas instituciones a otras. Asimismo, también contribuyeron a la formación y renovación del corpus de libros litúrgicos de los monasterios mediante la adquisición y donación de manuscritos, generalmente pertenecientes al oficio de la Orden, pero no siempre. Por último, participaron activamente en la composición y ordenación de nuevos libros, como fue el caso de la famosa Constanza de Castilla, priora de Santo Domingo el Real de Madrid, ${ }^{41}$ o bien interpolaron diversos textos como legendae en la liturgia, dotándola así de un carácter propio, en el que el influjo local fue notable.

Dejando a un lado estas cuestiones de la intervención femenina en la elaboración y desarrollo de la liturgia, que sin duda merecen ser abordadas en mayor profundidad y con mucho mayor detalle en otro lugar, y volviendo a las fuentes, pese a la manifiesta escasez, una búsqueda exhaustiva en archivos y bibliotecas sacaría probablemente a la luz manuscritos y fragmentos desconocidos. Lógicamente, tanto el estudio individual como de conjunto de tales fuentes arrojaría luz sobre las particulares características y el desarrollo de la liturgia de las monjas dominicas de Castilla durante la Edad Media. ${ }^{42}$

Sin embargo, junto a los códices litúrgicos, existen otras fuentes que deben ser tenidas en consideración cuando abordamos estos asuntos. En primer lugar, los edificios en sí, que sirvieron de contexto a la celebración litúrgica. Algunas características de los mismos pueden ayudar a formular hipótesis sobre las peculiaridades de la celebración de algunas partes del Oficio Divino. Junto a los edificios y determinadas imágenes, también otro tipo de fuentes escritas -contratos de construcción, testamentos, libros de devoción, libros destinados a la cura monialium, o bien crónicas monásticas-, pueden aportar también información destacada sobre la celebración litúrgica en un determinado monasterio..$^{43}$ En lo que respecta a estas últimas, lamentablemente, la situación ibérica tampoco es comparable en este aspecto a la germana o la italiana, pues las crónicas conservadas no son anteriores al siglo

\section{Sauer 2007.}

41 Véase al respecto la nota 43.

42 Aunque no centrado en monasterios de dominicas en Castilla, sino en Italia, cabe mencionar al respecto la tesis de Stefania Roncroffi sobre los libros litúrgicos de los monasterios de dominicas en Bolonia: Sant Agnese y Santa María Maddalena di Val di Pietra (Roncroffi 2009).

43 Un notable ejemplar entre los libros devocionales es el mencionado Libro de Devociones y Oficios, compilado entre 1462 y 1474 por Constanza de Castilla, priora de Santo Domingo el Real de Madrid y conservado actualmente en la Biblioteca Nacional de Madrid (BNE, Ms. 7495). Pese a tratarse de un pequeño volumen aparentemente dedicado a la devoción privada, algunas partes del mismo fueron empleadas, en realidad, en la liturgia comunitaria en el coro. Más aún, el Oficio de los Clavos, incluido en él, fue de hecho celebrado en el monasterio con permiso oficial tanto del papa como del maestro general de la Orden (Castilla 1998; Wilkins 1998). 
$\mathrm{XVI}^{4}{ }^{44}$ No obstante, dado que éstas recogen con frecuencia tradiciones, costumbres y prácticas perpetuadas durante siglos, deben ser tenidas en cuenta, aunque siempre desde una visión crítica de las mismas. ${ }^{45}$

ORIGEN Y DESARROLLO DEL CANTO PROCESIONAL DE LA SALVE REGINA EN LA ORDEN DE PREDICADORES

La liturgia dominica consistió en siete horas canónicas, que siguieron con estrecha fidelidad la liturgia coral de los monjes y los canónigos regulares, con excepción de completas. Ésta adquirió enseguida una estructura especial en la liturgia propia de la Orden convirtiéndose en la hora más solemne, por la variedad de antífonas, responsorios e himnos disponibles para la misma y, sobre todo, porque se cerraba siempre con el canto de la Salve Regina. ${ }^{46}$

Siguiendo el oficio monástico y canonical, los dominicos dividieron el oficio de completas en dos partes, la primera de las cuales tenía lugar en el refectorio, durante un pequeño refrigerio líquido que la Orden permitía, para dirigirse posteriormente en procesión hasta la iglesia. En cambio, fuera del período de ayuno, las completas se iniciaban en el coro. ${ }^{47} \mathrm{~A}$ continuación los frailes se encaminaban procesionalmente a la ecclesia laicorum, como se describía

44 La crónica del monasterio de Aveiro, una de las más antiguas en la Península Ibérica, fue redactada entre 1513 y 1525 por una monja dominica del mismo. Crónica da Fundação do Mosteiro de Jesus, de Aveiro, e Memorial da Infanta Santa Joana Filha del Rei Dom Afonso V. Gomes da Rocha Madahil, A (ed.). 1939. Aveiro: Francisco Ferreira Neves, Aveiro. Gilberto Corralejo Moiteiro (2013) ha realizado una tesis doctoral en el que se ocupa del estudio de este y otros textos normativos y memoriales que constituyeron y definieron la "comunidad textual» de las primeras dominicas de este monasterio portugués.

45 La situación es bien distinta en el ámbito alemán, donde los monasterios femeninos crearon un nuevo género literario, llamado Schwesternbücher o Vitae sororum, a imitación de las Vitae fratrum de Gerardo de Frachet. Un ejemplo destacado lo constituyen las Vitae sororum del monasterio de Unterlinden, compuestas en torno a 1320 por Katherine von Gueberschwihr (Ancelet-Hustache 1930). La importancia de estas crónicas radica en que fueron escritas por las propias religiosas, situación que cambió con la introducción de la reforma, cuando los frailes mediatizaron las crónicas escritas por las monjas, eliminando o modificando aquellas partes que consideraron poco convenientes. Así sucedió con los Schwesternbücher de Töss, Katharinental y Oetenbach, que fueron copiados y editados por Johannes Meyer o, en el caso italiano, con la crónica del monasterio de San Giorgio de Lucca (Winston-Allen 2004; Coli 2009). Sobre la importancia de estos textos, tradicionalmente despreciados y considerados fuentes poco atendibles, véase Lewis 1996.

46 El relevante papel de completas en la liturgia dominica fue ya destacado por Humberto de Romans en su comentario a la regla de San Agustín y al primero y segundo capítulo de las Constituciones de los frailes dominicos (Romans 1888-1889, I: 165). Sobre la música de los dominicos véase Asensio Palacios, Biain y Salvador Bermejo 2007: 93-95. Entre los estudios clásicos sobre Completas en la Orden de Predicadores, cabe mencionar Verwilst 1933; Rieland 1945 y Gorton 1949.

47 El tiempo de ayuno de los dominicos comenzaba el catorce de septiembre, festividad de la Exaltación de la Santa Cruz y finalizaba en Pascua. También eran días de ayuno las vigilias de las siguientes festividades: Ascensión, Pentecostés, San Juan Bautista, San Pedro y San Pablo, San Mateo, San Simón y San Judas, San Andrés, Santiago, Todos los Santos, así como las Témporas y los viernes. A esta lista San Raimundo de Peñafort añadió las vigilias de San Lorenzo y de la Asunción de la Virgen (Bonniwell 1945: 156). ya en las Consuetudines. ${ }^{48}$ Sin embargo, no se recogía en ellas el elemento más característico de esta hora litúrgica, esto es, el canto procesional de la Salve, que no se incorporó hasta fechas más tardías.

Los dominicosnofueron, de hecho, nilos creadores deesta antífona ni los primeros en emplearla procesionalmente. La Salve apareció por primera vez en el antifonario cisterciense, compilado entre 1134 y 1145, a consecuencia de la reforma litúrgica promovida por San Bernardo. ${ }^{49}$ Aunque en este libro no se menciona el canto procesional de la misma, este se documenta por primera vez poco después, pues aparece recogido por en los Statuta escritos para Cluny por Pedro el Venerable en 1145. En ellos se prescribía el canto de esta antífona durante la procesión del día de la Asunción, así como durante todas las procesiones celebradas a lo largo del año, desde la iglesia principal a la capilla de Santa María, situada en la huerta monástica. ${ }^{50}$

Dejando a un lado el dudoso testimonio de la Beata Cecilia, según la tradición de la Orden de Predicadores, la costumbre de cantar la Salve tras completas fue introducida en la liturgia dominica en tiempos del Beato Jordán de Sajonia, primer sucesor de Santo Domingo, aunque existen divergencias entre los distintos autores acerca de la fecha precisa. ${ }^{51}$ No obstante, entre todas estas fuentes, el relato más atendible parece ser el del propio Jordán de Sajonia, por ser autobiográfico y contemporáneo de los hechos. Siguiendo a este, recién nombrado provincial de Lombardía, Jordán se dirigió al convento de Bolonia para ver a Santo Domingo, encontrándose a su llegada, sin embargo, con la noticia de que el Fundador había fallecido recientemente, el 6 de agosto de 1221. Por entonces, un tal fray Bernardo, profeso en el convento boloñés, era víctima de ciertas invasiones diabólicas a las que tampoco fue ajeno el propio provincial y, a fin de poner remedio a tales males, los frailes boloñeses acordaron establecer como práctica el canto de la antífona Salve Regina

48 Con respecto a las constituciones de los frailes, la tesis tradicional, desde el estudio del Liber Consuetudines por Denifle, sostenía que el manuscrito de Rodez, conservado en el Archivo General de la Orden, contenía el Liber Consuetudines, con los estatutos aprobados en el capítulo general de 1228. Sin embargo, las investigaciones de Mandonet, Vicaire y Thomas al respecto han demostrado que al texto de 1228 se le fueron realizado diversas adiciones correspondientes a los sucesivos capítulos generales, hasta el año de 1241. AGOP, Cod. XIV, A4 (Denifle 1885). Un estudio crítico de todas estas adicciones ha permitido individuar aquellas disposiciones que provendrían de las Consuetudines dadas entre 1215 y 1216 por Santo Domingo a la Orden recientemente fundada (Thomas 1965).

49 Una de las copias más antiguas del antifonario cisterciense, procedente de la abadía de Morimondo, se conserva en la Biblioteca Nacional de Francia. (BNF, Départament des manuscripts, Nouvelles acquisitions latines, Ms. 1412). La antífona Salve Regina aparece como antífona ad Evangelium en las cuatro principales festividades marianas (Canal Sánchez-Pagín 1963: 37-47 y 57-61).

50 Pedro el Venerable. 1890. Statuta cluniacensia (c.annos 11461147 compilata), Statutum 76, en Migne (ed.) 1890: 1049.

51 Según sor Cecilia, ya en tiempos de Santo Domingo existía la costumbre entre los dominicos y dominicas de Roma de recitar, sin canto, la Salve Regina diariamente. Cfr. Walz 1967: 33; Cecilia Cesarini, Beata. «Relación de los milagros obrados por Santo Domingo en Roma», en Gelabert, Milagro y Garganta 1966: 414-416. Sin embargo, debemos tomar con cuidado las palabras de Cecilia, teniendo en cuenta las fechas tardías de la redacción de esta obra, que fue dictada por ésta a sor Angélica en el convento de Bolonia entre 1272 y 1288. 
tras completas. ${ }^{52}$ Esta práctica se extendió enseguida a todos los conventos de la Provincia de Lombardía y poco después debió hacerse oficial y obligatoria para toda la Orden, en alguno de los Capítulos Generales celebrados tras la elección de Jordán como maestro general el 22 de mayo de 1222 . No obstante, cabe señalar que en el relato de este solo se habla del canto de la antífona sin hacer referencia a la procesión..$^{53}$ En cambio, ésta sí aparece descrita con todo detalle apenas unos años después en el Ordinario, que formaba parte del Ecclesiasticum Officium, como se ha visto. ${ }^{54}$

La magna tarea reformadora de Humberto de Romans comprendió también la promoción del culto mariano en la Orden, a la que contribuyeron una serie de textos propagandísticos, escritos por Tomás de Cantimpré, Gerard de Frachet y el propio Romans, en los que se defendía la predilección de la Virgen por los dominicos, lo cual venía apoyado por una serie de historias milagrosas..$^{55}$ Por último, el papel de la Virgen como protectora oficial de la Orden se completó, además de con los mencionados relatos y con la inclusión del canto procesional de la Salve tras completas, con la reforma de las festividades marianas, mediante la adición de secuencias dedicadas a Nuestra Señora. ${ }^{56}$

Volviendo al canto de la Salve, sucesivos capítulos generales establecieron su obligatoriedad para todos los miembros de la Orden, algo en lo que se insistió especialmente durante la reforma, como evidencian, por ejemplo, las disposiciones dadas por el maestro general Vicente Bandelli a la provincia de España, tras su visita a ésta en $1504 .{ }^{57}$ Aunque, como se ha visto, no fuese una práctica exclusiva de los dominicos, no puede negarse que ellos la dotaron de mayor solemnidad y la asociaron a completas, contribuyendo a la difusión de tal práctica fuera de la Orden. Así, el papa Gregorio IX, influenciado por fray Raimundo de Peñafort, ordenó que en todas las iglesias de Roma se cantase la Salve todos los viernes tras completas. En 1249, el rito franciscano adoptó la costumbre de recitar tras la última hora del oficio una de las cuatro antífonas de Nuestra Señora, incluyendo la Salve. ${ }^{58}$ Dos años después, la costumbre de terminar completas con la Salve fue introducida entre los cistercienses, y también pasó a formar parte de la liturgia benedictina a comienzos

52 «Esta tremenda vejación de fray Bernardo, fue la causa principal que nos impulsó a establecer en el convento de Bolonia el canto de la antífona Salve Regina después de completas. De aquella casa comenzó a extenderse esta piadosa y saludable costumbre a la provincia de Lombardía y, finalmente, a toda la Orden» (Sajonia, J. de 1987 [1935]. «Orígenes de la Orden de Predicadores», en Galmés y Gómez: 122-123).

53 Bonniwell 1945: 165.

54 «De antiphona cantanda post completorium ad recommendandum ordinem et fratres Beatae Virgini», Ordinarium iuxta ritum Sacri Ordinis 1921: 120-121.

55 Cantimpré 1895; Frachet, G. de 1987 [1896]. Vitae Fratrum ordinis Praedicatorum, en Galmés y Gómez (eds.) 1987: 410-411; Romans 1888-1889, II: 131.

56 Fassler 2004: 231-238.

57 González Fuente 1981: 246; Hernández Martín 1981: 11 y 91.

58 San Buenaventura aconsejó también a los novicios franciscanos el rezo del Oficio de la Virgen, seguido del salmo Miserere y de la Salve Regina en las fiestas dobles. San Buenaventura, "Regula Novitiorum», en Opera omnia. 1888-1902. VIII: 476. Quaracchi: Collegium S. Bonaventurae, cit en Canal Sánchez-Pagín 1963: 91. de la siguiente centuria. ${ }^{59}$ Finalmente, el dominico Pío V estableció la Salve Regina como antífona final del oficio de completas en la liturgia romana, junto con las otras cuatro antífonas marianas.

Tal costumbre también se difundió fuera de la iglesia oficial, entre los laicos, como prueban las referencias en los milagros recogido por Gonzalo de Berceo, o la curación de una sordomuda en Puy, en la Cantiga 262 del Códice Rico de la Biblioteca del Escorial. ${ }^{60}$

Según se recoge ya en el ordinario de Romans, y posteriormente en el ceremonial dominico, el canto de la Salve tenía lugar todos los días, con excepción del Miércoles, Jueves y Viernes Santo. Dos acólitos, vistiendo sobrepellices y portando candeleros con velas encendidas, se situaban delante del altar. Con la nota inicial toda la comunidad se ponía de rodillas y permanecía en esta posición hasta que la palabra Salve hubiese acabado. Entonces se alzaban y participaban en el canto, los frailes abandonaban sus sitiales y formaban en procesión detrás de los dos acólitos, que iban delante hacia la iglesia exterior o de los laicos. Cada uno de ellos hacía una reverencia con la cabeza al pasar junto al gran Crucifijo situado entre el coro y la iglesia, siendo posteriormente rociados con agua bendita. Sin embargo, según el ordinario, cuando la ecclesia laicorum no estuviese disponible, o cuando únicamente se encontrasen presentes un reducido número de frailes, se les aconsejaba permanecer en el chorus. ${ }^{61}$

Posteriormente fue introducida la costumbre de que la comunidad se arrodillase al decir las palabras Eia, ergo, advocata nostra debido a una visión relatada por Jordán de Sajonia. ${ }^{62}$ Ya en el siglo XIV comenzó a ser frecuente

59 Bonniwell 1945:154-155; Canal Sánchez-Pagín 1963: 117.

60 Se trata de los milagros IX, XXI y XXIV, Berceo 1997: 76, 130 y 189; Alfonso X, Cantigas de Santa María, ed. facsímil del códice T. 1.1 (Códice Rico) de la Biblioteca de el Escorial, 1979: 13 Madrid: Edilán, cit. en Álvarez Díaz 2004: 152.

61 Ordinarium iuxta ritum Sacri Ordinis: 120-121, n.481. Cfr. también. "De Officio Ecclesiae» in Romans 1888-1889, II: 131-138. El término chorus fue sustituido en la segunda mitad del siglo XIII por ecclesia fratrum o ecclesia interior, es decir, la zona destinada a los frailes. En trabajos citados en notas anteriores, Costantino Gilardi realizó una interpretación funcional de la arquitectura de las iglesias dominicas en función de las disposiciones del Ordinarium, y otros libros del Ecclesiasticum Officium, así como de las mutaciones y variaciones introducidas posteriormente en la legislación de la Orden al respecto. Véase nota 7 y nota 11 . Recientemente, Joanna Cannon ha retomado estas cuestiones, dedicando un capítulo entero, que titula precisamente The Salve Regina Procession and the Screen, a analizar esta división de la iglesia dominica a partir de la descripción de la procesión de la Salve en el Ordinario de 1256. En él estudia analiza las evidencias de existencia de tramezzi en las iglesias dominicas de los siglos XIII y XIV, con particular interés en la Provincia Romana, a la que está dedicado el libro, mientras que las imágenes del Crucificado y la Virgen se analizan en capítulos posteriores (Cannon 2013: 25-45). El desarrollo de la procesión de completas ha sido representado con frecuencia. Además de la conocida pintura de Pedro Berruguete, conservada en el Museo del Prado, cabe mencionar otra tabla procedente del convento dominico de Utrecht, y una miniatura del salterio y libro de horas de Alfonso el Magnánimo, ilustrado por Leonardo Crespi y completado en 1443. La tabla holandesa se conserva en el Catharikneconvent Museum, Utrecht ( $A B M$ s00071). Por su parte, el salterio del Magnánimo se encuentra en la British Library BL, Ms. Add. 28962, f. 263v. (Español Beltrán 2002-2003: 98 y112).

62 Fue establecido en el capítulo general de Toulouse de 1258, en consecuencia, tal disposición no aparece en las Constituciones de los frailes de 1256, pero sí en las de las monjas. «Item hanc. In capitulo de inclinacionibus. ubi dicitur. et quando nomen beate virginis nominatur 
FIGURA 3

Santo Domingo el Real de Toledo. Reconstrucción del estado del monasterio a inicios del siglo XVI con la nueva panda meridional del claustro del moral (1507-1508). (Realizado sobre el plano del instituto Geográfico y Estadístico, 1881)

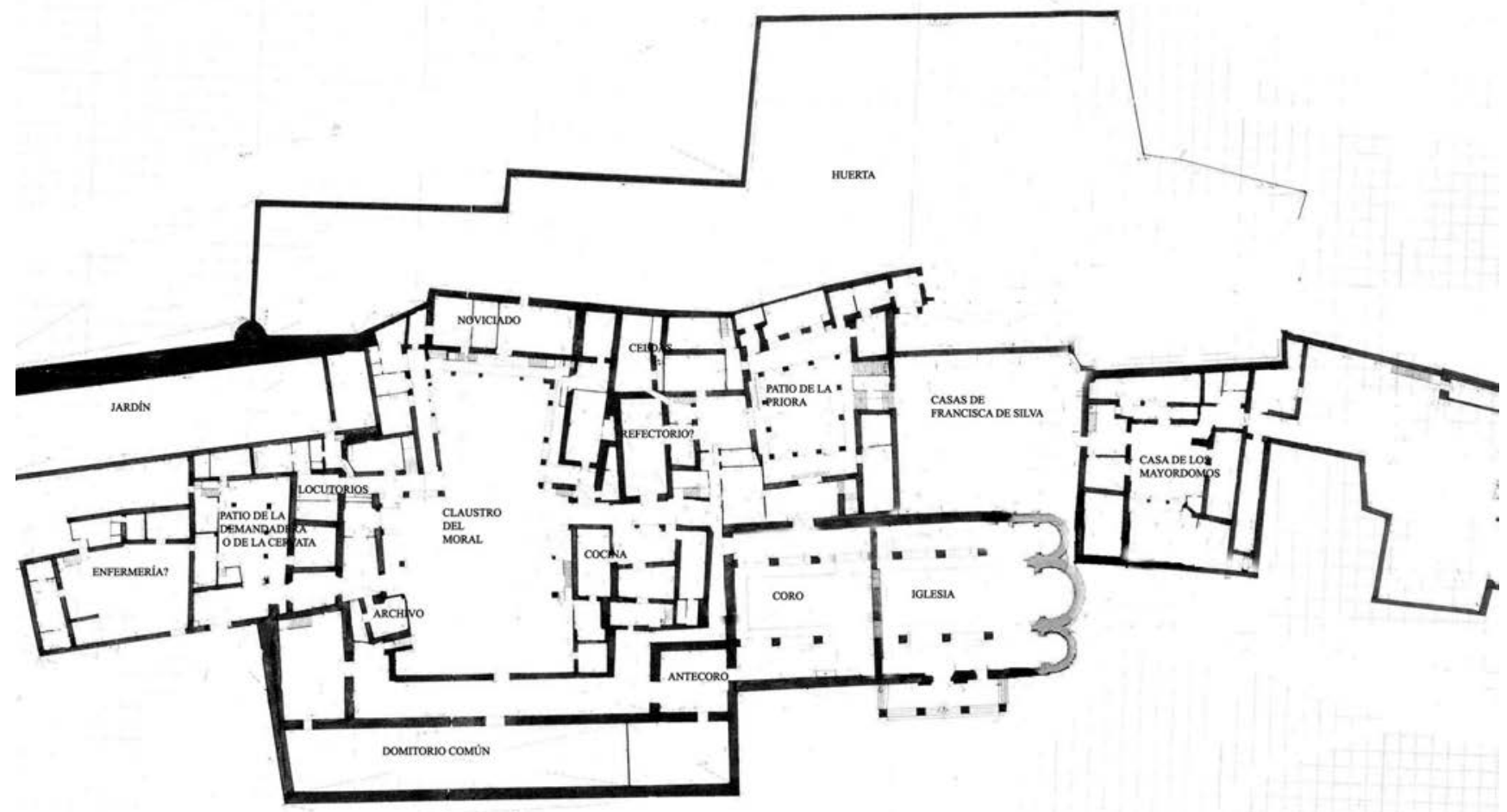

la práctica de cantar la antífona O lumen Ecclesiae, de la fiesta de Santo Domingo, mientras los frailes regresaban al coro en procesión, finalizando con los versos y la colecta del santo, aunque en algunas provincias y conventos tal antífona fue reemplazada por otra. En Castilla, el capítulo de la Congregación de la Observancia celebrado en Salamanca en 1489 estableció distintas antífonas para ser cantadas según el día de la semana. ${ }^{63}$

DESARROLLO Y CONTEXTO DE LA LITURGIA PROCESIONAL DE COMPLETAS EN LOS MONASTERIOS DE LAS DOMINICAS CASTELLANAS

\section{Canto procesional de la Salve Regina}

Hasta aquí, todos los textos traídos a colación estaban destinados a los frailes y, como se ha visto, las monjas

ad antiphonam. salve. deleatur hoc. et infra in eodem capitulo. ubi dicitur. veni sancte spiritus. addatur. et ad antiphonam salve. quando nomen beate virginis nominatur». Acta capituli generalis Tholose celebrati anno Domini MCCLVIII, MOPH 3 (1220-1303), Constitutiones et Acta Ordinis Fratrum Praedicatorum: 1232-2001: 356 (cf. MOPH 3, P. 91) (Bonniwell 1945: 161-162; Sajonia, J. de [1935]. "Orígenes de la Orden de Predicadores», en Galmés y Gómez 1987: 122-123). Posteriormente, Gerardo de Frachet ([1896], en Galmés y Gómez 1987: 411-414) recogió varios hechos milagrosos, relativos a la antífona, acontecidos en el convento de los frailes de París, en Marsella, en Tarascón, en Cambridge, en otra desconocida ciudad inglesa y en Prouilhe.

63 Los martes la antífona debía estar dedicada a San Pedro Mártir los miércoles a Santo Tomás de Aquino y los jueves a San Vicente Ferrer. El resto de los días de la semana se dedicaba a Santo Domingo y también el domingo en el que se cantaba el $O$ lumen (Hernández Martín 1980: 50). no dispusieron de libros escritos específicamente para ellas hasta el siglo XIX. En uno de estos, el ceremonial de Ambrosio María Potton, se indicaba que, dado que a las monjas no les estaba permitido acceder a la ecclesia laicorum, la procesión de completas había de desarrollarse exclusivamente en el coro. ${ }^{64}$

Siguiendo esto, en el monasterio de Santo Domingo el Real de Madrid, el canto de la Salve tenía lugar ante el altar de la Virgen de la Misericordia, una de las imágenes más antiguas del monasterio, que estaba situada en el coro monástico, cerca del comulgatorio. Esto resulta perfectamente lógico si tenemos en cuenta la estrecha relación que existió entre el canto de esta antífona y el desarrollo de esta devoción mariana, asociadas ambas a la promoción de la Orden, a través de la protección y amparo de la Virgen, como se ha visto. Ante esta Mater Misericordiae se arrodillaban las religiosas al llegar a las palabras centrales Eia, ergo, advocata nostra, como era costumbre en la Orden. ${ }^{65}$ De igual forma, las dominicas de Santa María de Medina del Campo, entonaban la Salve portando cirios ante la citada imagen de la Virgen de los Huertos, situada en el lado del Evangelio del coro. ${ }^{66}$

No obstante, testimonios arquitectónicos y documentales prueban que, en muchos casos, las procesiones asociadas a completas no tenían lugar ni en el chorus ni en la ecclesia laicorum, sino que se desarrollaban en el claustro y otras dependencias, siguiendo en ocasiones el desarrollo de otras procesiones.

\footnotetext{
64 Potton 1900: 245.

65 Quintana 1629: 397 r y v; Russo 1996: 269.

66 Medrano 1734, Tercera parte, I: f. 70.
} 
Una clara prueba de esto la tenemos en el monasterio de Santo Domingo el Real de Toledo, en concreto en el llamado claustro del Moral. En 1507 se inició una completa reconstrucción de este, pero los trabajos fueron interrumpidos en 1508, cuando solo se había concluido la panda meridional y los arranques de las pandas oriental y occidental. ${ }^{67}$ La panda sur, de cuarenta metros de largo, consta de tres plantas diáfanas, es decir, sin tabiques internos. Al menos una de las dos primeras estuvo probablemente destinada a dormitorio común, mientras que en la planta baja debió ubicarse el refectorio. Por último, de acuerdo con la tradición monástica, el piso superior se destinó a hacer penitencia y rezar el Miserere los viernes de Cuaresma, ante una Piedad o una Crucifixión, el llamado "Cristo de las Aguas». ${ }^{68}$

Ciertas peculiaridades de esta panda claustral -algunas actualmente existentes y otras conocidas gracias a las fuentes documentales y gráficas- apoyan claramente su uso como escenario de las procesiones asociadas a completas. El primero de estos elementos es una inscripción que recorre el friso situado debajo del alfarje que cubre la panda. En la actualidad se encuentra bastante deteriorada pero, según puede verse en fotografías del siglo XIX pertenecientes al fondo Rodríguez, del Archivo Histórico Provincial de Toledo, se hallaba en mucho mejor estado en aquel momento y puede apreciarse cómo también corría sobre la cara interna de la arquería, siendo cercenada posteriormente. ${ }^{69} \mathrm{~A}$ pesar de su actual estado, los fragmentos conservados permiten afirmar que se trata en efecto de la citada antífona $O$ lumen, que se cantaba tras la Salve de regreso al coro: O Lumen Ecclesiae, Doctor veritatis, Rosa patientiae, Ebur castitatis, Aquam sapientiae propinasti gratis: Praedicator gratiae, nos junge beatis.

Un segundo elemento sería la existencia, según recoge la tradición conventual, de un altar dedicado a Santo Domingo en esta panda al que se dirigiría otra de las procesiones que tenían lugar tras completas y de la que hablaré más adelante. ${ }^{70}$ Por último, gracias a fotografías conocemos también la existencia de una pintura que representa a Santo Tomás orante ante un Crucifijo, según una leyenda del santo contenida entre otras fuentes en el Codex Matritensis y que posiblemente se ubicó en otro altar o estación de esta panda claustral. ${ }^{71}$

Asimismo, en esta panda o en sus proximidades debió existir otro dedicado a la Virgen, ante el cual quizás iniciaba el canto de la Salve, o bien al que se dirigía la procesión celebrada los sábados tras completas, que será comentada más adelante. En una fotografía del citado fondo Rodríguez puede observarse una curiosa pintura mural, situada sobre un altar de azulejos claramente posterior y que parece haber estado oculta en fechas anteriores. Aunque se encuentra bastante deteriorada, en ella puede verse una representación

67 AMSDRT, Doc. 360, Cuenta de los maravedís que se gastaron en las casas de los confesores. Año 1507-1508, Íbidem Doc. 361, Noticias de las obras en la crujía nueva del Patio del Moral, 1508. También noticias de la casa de los confesores.

68 Sierra Corella 1935: 307.

69 AHPT, Fondo Rodríguez F-020-01

70 De acuerdo con la leyenda, dos monjas dominicas estaban hablando en esta panda cuando Santo Domingo salió de un altar cercano y batió las palmas fuertemente ordenando silencio (Sierra Corella 1935: 307).

71 Galán Vera 2010: 756.
FIGURA.4

Santo Domingo el Real de Toledo. Panda meridional del Claustro del Moral (AHPT, Fondo Rodríguez F-020-01)

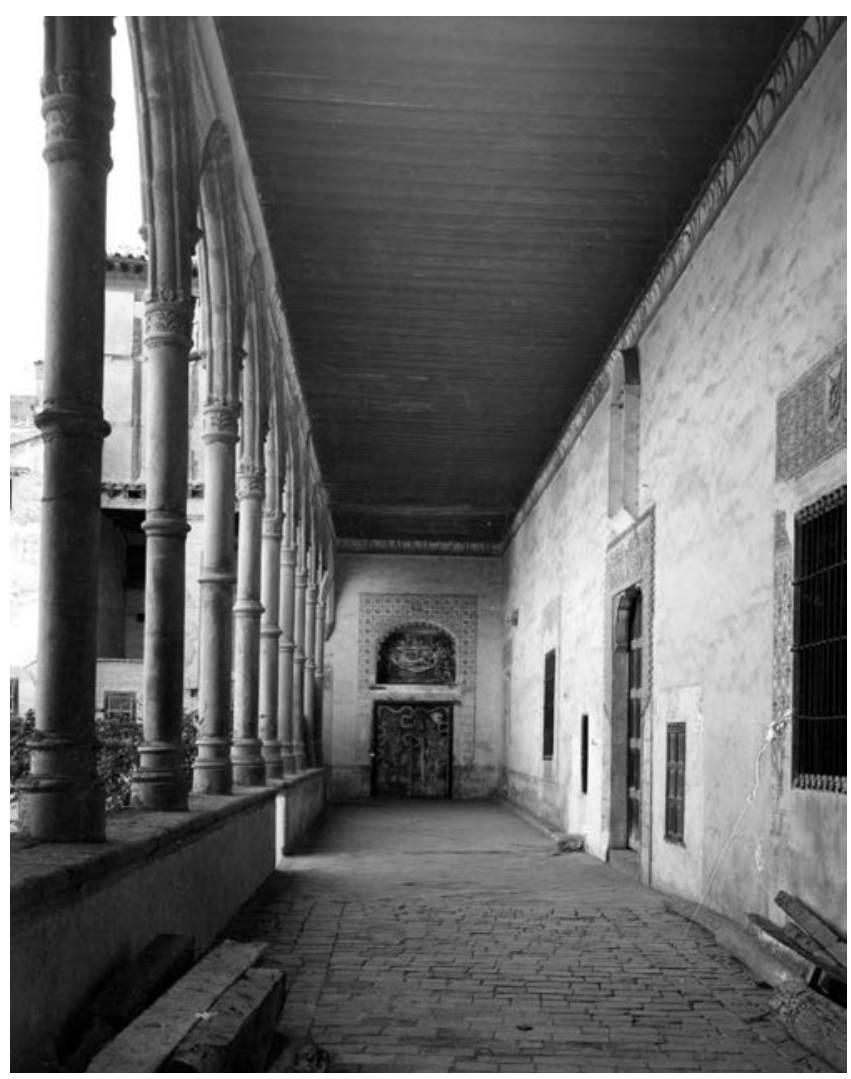

FIGURA 5

Santo Tomás de Aquino meditando ante el Crucifijo. Santo Domingo el Real de Toledo. Desaparecida. (AHPT. Fondo Rodríguez. F. 49)

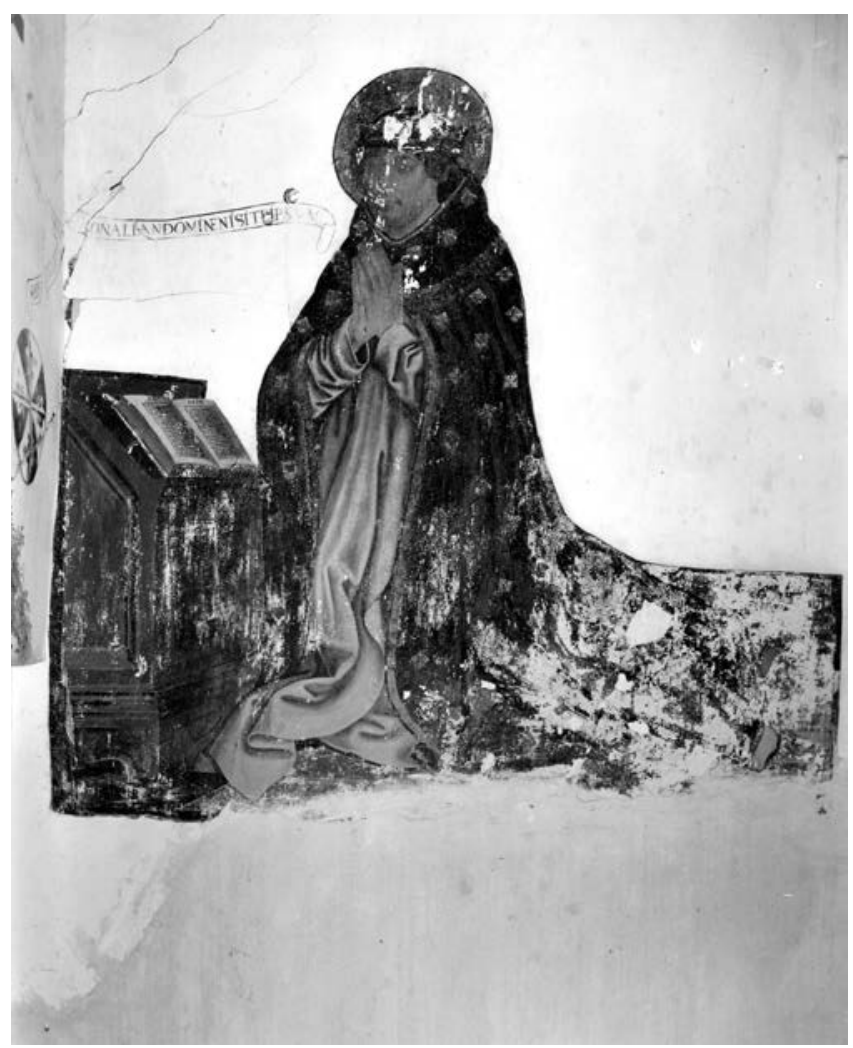


FIGURA.6

Virgen de la Misericordia y santo dominico. Pintura mural desaparecida. Santo Domingo el Real de Toledo. (AHPT Fondo Rodríguez CMC-249)

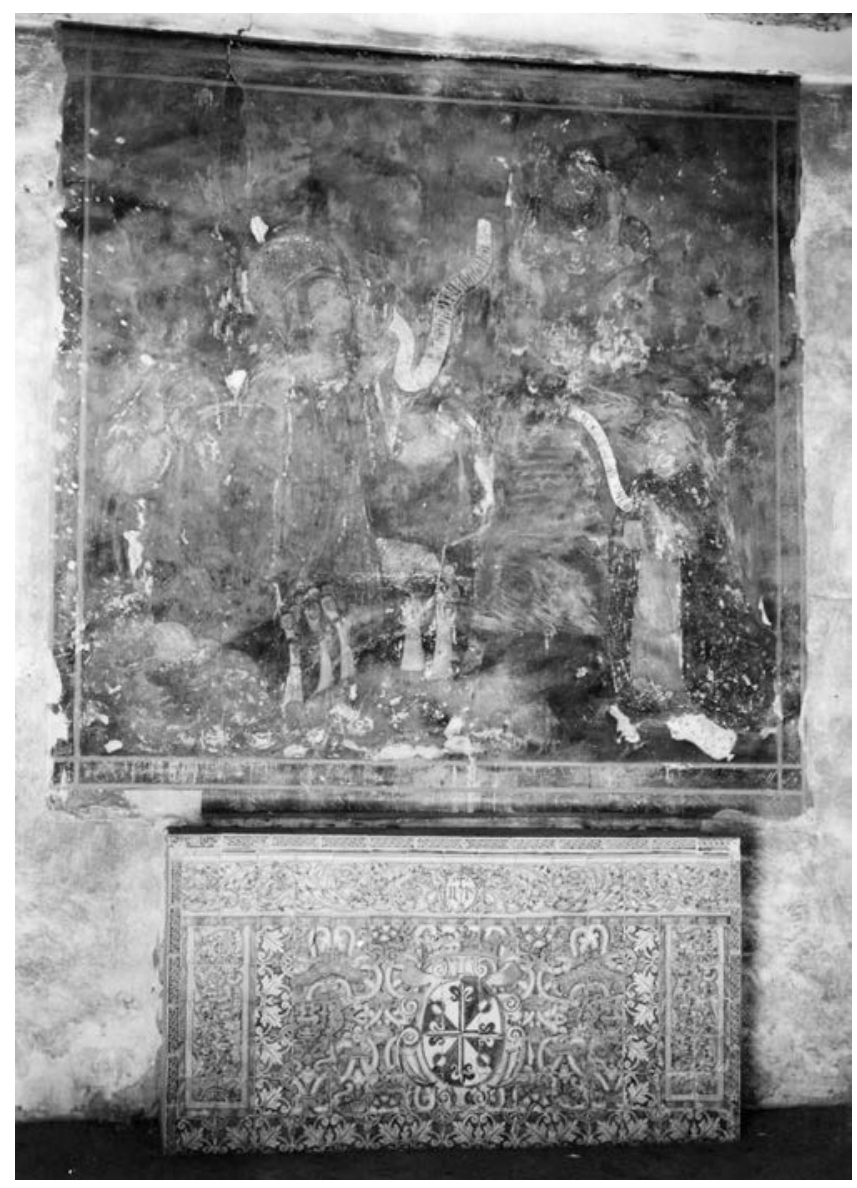

de la Virgen de la Misericordia, con una serie de religiosas dominicas bajo su manto, en actitud orante y la mirada elevada al cielo. Frente a Nuestra Señora se sitúa otra figura, aparentemente masculina, nimbada y vestida con el hábito dominico. Se trataría por tanto de un santo dominico que dialoga con la Virgen, aunque tampoco el texto de las filacterias, que resultaría clave para la interpretación de la escena, es legible. Pese a la dificultad de su identificación iconográfica, me atrevo a sugerir la posibilidad de que se tratase la representación de una de las apariciones de la Virgen a Santo Domingo relatadas por la Beata Cecilia. Según una de ellas, una noche, mientras se hallaba en oración, Santo Domingo pudo ver cómo la Virgen, en compañía de Santa Cecilia y Santa Catalina de Alejandría bendecía a los frailes en el dormitorio. Posteriormente, en una segunda aparición a Santo Domingo, la Virgen estaba sentada a la derecha de Cristo, rodeados ambos por religiosos de todas las órdenes, excepto dominicos. Sin embargo, ante la aflicción del Santo, Nuestra Señora abrió su manto mostrando a dominicos y dominicas cobijados bajo aquel, como símbolo de su especial predilección. Tal visión fue referida por el Fundador a Sor Cecilia y las hermanas de San Sixto. ${ }^{72}$ La representación

72 AHPT, Fondo Rodríguez, CMC-249. Cecilia Cesarini, Beata. "Relación de los Milagros obrados por Santo Domingo en Roma», en Galmés y Gómez (eds.) 1987: 675. de este episodio no es muy conocida, por haber sido sustituida a partir de finales del xv por la entrega del Rosario a Santo Domingo por parte de la Virgen, frecuentemente acompañados por santos y santas de la Orden.

Ahora bien, ¿dónde estaba este altar? Aunque su iconografía podría llevarnos a situarlo en esta panda claustral, lo cierto es que su factura indica una cronología claramente anterior a la construcción de la misma. No obstante esto no es óbice para relacionarlo con las procesiones asociadas a completas, puesto que éstas, como se verá, podrían discurrir también por otras dependencias.

Además de estos altares, la plausible localización del refectorio en la planta baja de esta panda puede relacionarse también con la celebración de completas, dado que, como se ha visto, su primera parte tenía lugar en el refectorio, durante el tiempo de ayuno, hasta el capítulo general de Salamanca de $1551 .^{73}$ Por último, lógicamente, lo más factible es que el desarrollo de esta compleja liturgia, junto a las antífonas y responsorios empleados en la misma, estuviese contenido en un procesionario, perdido o desaparecido, probablemente posterior a la elaboración de la última parte del mencionado breviario portátil.

\section{Otras procesiones asociadas a completas}

Además de la procesión de la Salve común a toda la Orden, existieron otras procesiones secundarias asociadas a completas, cuya celebración varió notablemente no solo de unas provincias a otras, sino incluso de un monasterio a otro. Entre ellas destacó la que tenía lugar los sábados a un altar dedicado a la Virgen y cantando una letanía mariana propia de la Orden, que se interpolaba entre la Salve y el O Lumen, y que concluía con el canto de la prosa Inviolata y su colecta. ${ }^{74}$ Aunque anteriormente se cantaron otras letanías, en 1614 se incorporó al breviario dominico la del Loreto -que había sido aprobada por Pío V en 1587-, algo que ratificó el capítulo general de 1615 . Sea como fuere, el canto de letanías marianas era algo habitual desde hacía tiempo en las capillas de las cofradías del Rosario, de donde debió pasar al oficio de completas dominico. ${ }^{75}$

73 En el contexto de la simplificación del Oficio, llevada a cabo por este Capítulo General, se estableció que la primera parte del oficio de completas se celebrase también en la iglesia, incluso durante el tiempo de ayuno (González Fuente 1981: 246).

74 Caeremoniale iuxta... 1869: 523. El Procesionarium de la Orden de Predicadores de 1609, realizado por el padre Damaso Artufel y conservado en la Biblioteca del Instituto Litúrgico de la Orden en Roma, cuenta con un cuadernillo añadido, titulado Adiciones al Procesionario a petición de algunos Padres muy graves con que se satisfaze el deseo de todos los Religiosos y Religiosas de la Orden y queda acabado y perfecto, y obra del padre Toribio Vélez de las Cuebas, en el que se recoge, en las páginas 259-261 la Letanía de Nuestra Señora, que se canta los Sábados después de la Salve en San Pedro de Roma, y en la Minerva, y en casi en todos los conventos de nuestra Orden de Italia, por un Breve del beatíssimo padre Gregorio XIII. Y por que se tiene esta misma devoción en muchos Conventos de España, y de las Indias, se pone aquí. Sus invocaciones son muy distintas de la letanía de Loreto (González Fuente 2003: 22).

75 Un libro publicado en Roma en 1593 incluía ya la música compuesta por Palestrina para «la letanía mariana que se acostumbraba a cantar en las capillas del as cofradías del Rosario». Ésta se dividía en cinco partes, correspondientes a las cinco decenas del Rosario (Bonniwell 1945: 328). 
En la festividad de la Inmaculada las dominicas madrileñas celebraban una procesión, portando una imagen de la Virgen por distintas dependencias monásticas, incluidas las celdas y el noviciado, y cuyo desarrollo no difería de la procesión mariana celebrada los sábados tras completas. ${ }^{76}$ Dado que tal costumbre debió ser anterior al citado capítulo de 1615, es probable que las dominicas madrileñas hubiesen contado con una letanía propia, que bien pudo haber sido la incluida en el ya citado Libro de Devociones de Constanza de Castilla, tras los Gozos y Dolores de la Virgen. ${ }^{77}$

La celebración de la fiesta de la Inmaculada en un monasterio dominico podría parecer algo extraño, dada la oficial postura maculista de la Orden de Predicadores. No obstante, debemos tener presente que también existieron voces disidentes al respecto en el seno de la Orden y que tanto la influencia del contexto social y religioso, como de determinados patronos fue frecuentemente más fuerte que la ejercida por la Orden de Predicadores. ${ }^{78}$ En efecto, la procesión celebrada en el monasterio madrileño surgió, probablemente, a imitación de la celebrada en la villa de Madrid en la festividad de la Inmaculada, desde 1348, momento en que fue instituida para agradecer a la Virgen la erradicación de la peste. ${ }^{79}$

Por otra parte, esta fusión entre distintas festividades o advocaciones marianas y las procesiones tras completas fue algo habitual y, lógicamente, se dio especialmente con la devoción a la Virgen del Rosario, una vez que ésta alcanzó su pleno desarrollo y se difundió por Europa, a finales del XV. ${ }^{80}$ Por ejemplo, la crónica de Santo Domingo de Lekeitio describía el desarrollo de una procesión que tenía lugar los domingos o festivos tras completas, rezando el Rosario, desde el coro, situado precisamente ante la capilla dedicada a esta advocación mariana, y recorriendo las distintas dependencias monásticas, para finalizar en una gran sala, desde la cual se podía contemplar el cementerio de la villa:

76 Arbeteta Mira 1996: 38. Procesiones similares tenían lugar en otras clausuras madrileñas, portando una imagen de la Inmaculada, algunas de las cuales fueron realizadas por escultores e imagineros de la talla de Luisa Roldán, Gregorio Fernández, Martínez Montañés o Pedro de Mena, entre otros (Sánchez Hernández 1994).

77 Castilla 1998: 81-89

78 La controversia existente en el seno de la Orden sobre la Inmaculada Concepción fue consecuencia de la obligación, establecida en el Capítulo General de 1279 de enseñar la doctrina de Santo Tomás de Aquino quien, como es sabido, adoptó una posición maculista. En consecuencia, en sustitución de la fiesta de la Inmaculada que comenzaba a ser aceptada, el capítulo General de 1388 instauró la fiesta de la Santificación (Bonniwell 1945: 230-231 y 256-268). No obstante, ya desde el siglo XIV, existieron en seno de la Orden voces favorables a la Inmaculada, como prueba la inserción de esta festividad mariana en algunos libros litúrgicos desde esta centuria. En el Concilio celebrado en Basilea en 1387 tuvo lugar una notable controversia al respecto, que contrapuso, por un lado a los franciscanos Jean de Rouvroy y Pierre Porcher, favorables a la Inmaculada y, por otro los dos dominicos, Juan de Montenegro y Juan de Torquemada. Este último, sin embargo, no llegó a exponer su posición en el Concilio, por surgir otros problemas más perentorios. Años más tarde dio a la luz su Tractatus de veritate Conceptionis beatissimae Virginis, en la que, como él mismo indicó en el título completo, más que exponer su postura, da cuenta de las distintas opiniones vertidas por los padres conciliares. Aunque muchos dominicos continuaron defendiendo la causa maculista en la centuria siguiente, a partir del XVI está postura se debilitó hasta que ya en el XVI la balanza se inclinó claramente a favor de las posturas inmaculistas. Sobre estas cuestiones, véase Horst 2009 y Rucquoi 2012: 629.

79 Muñoz Fernández 1990: 160-162.

80 Alonso Getino 1925; Labarga García 2003: 228-229.
Después de completas o bien después de rezar en el coro Vísperas, Completas y Rosario, salía toda la Comunidad en procesión por todo el convento rezando el Rosario, del modo siguiente. Se empezaban en el coro, la sacristana salía la primera rociando todos los rincones con agua bendita, del coro se dirigía la procesión al dormitorio viejo del piso de arriba, y cuando se llegaba al último extremo, o sea junto al ropero viejo, se suspendía el rezo del Rosario y se rezaba un responso con la oración Quaesumus domine. Se rezaba en este lugar este responso porque más arriba en un rincón se guardaban las andas en que se llevaba a enterrar a las religiosas difuntas. Continuaba el rezo del Rosario bajando por la otra escalera al piso segundo y se dirigía la procesión al refectorio, dándose una vuelta por él y después se bajaba al claustro (donde está la leña). Después se dirigía la procesión al comulgatorio viejo y colocadas en él volvían a suspender el rezo del Rosario y se rezaba el Salmo De Profundis con dos o tres oraciones por las religiosas difuntas que allí estaban sepultadas. Después volvía a tomar su marcha la procesión rezando y echando agua bendita por unos caminitos estrechos y tortuosos que había en la planta baja, teniendo que caminar unas detrás de otras por no tener sitio para ir de dos en dos hasta llegar a un salón viejo, que tenía un corredor o balcón grande que miraba hacia el cementerio de la villa, allí nos arrodillábamos todas hasta concluir el rezo del Rosario y se ponía fin con un responso para sacerdote según la oración y después otro Salmo De Profundis con las oraciones correspondientes para muchos(....). ${ }^{81}$

Aunque la crónica no es anterior a inicios del xx, es muy probable que esta procesión se celebrase en el monasterio desde fechas muy anteriores, dada la conocida pervivencia de prácticas litúrgicas desde la Edad Moderna, o incluso medievales, hasta la celebración del Concilio Vaticano II, como está perfectamente documentado en otros casos.

Además, dicha procesión resulta especialmente atractiva por combinar diferentes elementos, no solo de la liturgia de completas y la devoción al Rosario, sino también de del oficio de difuntos. En lo que respecta a las oraciones y salmos procedentes de este último e interpolados durante la procesión, la recitación de la oración Quasumus domine en el lugar donde se custodiaban las andas de las religiosas resulta del todo lógica dado que, según se recoge ya en el ordinario de Humberto de Romans de 1256, ésta era la que se decía en memoria de los difuntos cuando se trataba de mujeres, si vero femina. ${ }^{82}$ A ésta se suma el salmo De Profundis, que acompañaba tanto la administración de la extremaunción y el viático, como la penitencia tras completas y también formaba parte del oficio de la Virgen del sábado. Por otra parte, también fue habitual lo contrario, esto es, la interpolación de la Salve Regina en el oficio de difuntos, acompañando la agonía de frailes y monjas, una vez que les habían sido administrados los últimos ritos y se había realizado la commendatio animae. De esta manera, los dominicos, y cabe suponer que también las dominicas, expiraban en las manos de la Mater Misericordiae. ${ }^{83}$

\footnotetext{
81 AMSDL, Crónica de Santo Domingo de Lequeitio, elaborada por Sor Tomasa Gregoria de Santa Inés y Pozo García, 1912, II: 49-50

82 Ordinarium iuxta ritum Sacri Ordinis: 120.Cfr. Caeremoniale iuxta ritum sacri orinidis: 607

83 Esta costumbre fue introducida en la Orden a consecuencia del martirio del Beato Sadoc y sus compañeros de Sandomir, acaecido en 1260 en Polonia, los cuales, según la tradición dominica, murieron cantando la Salve (Lippini 2008 [1990]: 305). Asimismo, las Vitae Fratrum relatan varios episodios de apariciones de la Santísima Virgen a enfermos y moribundos, como fue el caso de un fraile del convento de Metz,
} 
FIGURA 7

Santo Domingo de Lekeitio. Estado actual del monasterio. Planta Baja. (Sobre plano de Jesús Muñoz-Baroja y José Garritxo)

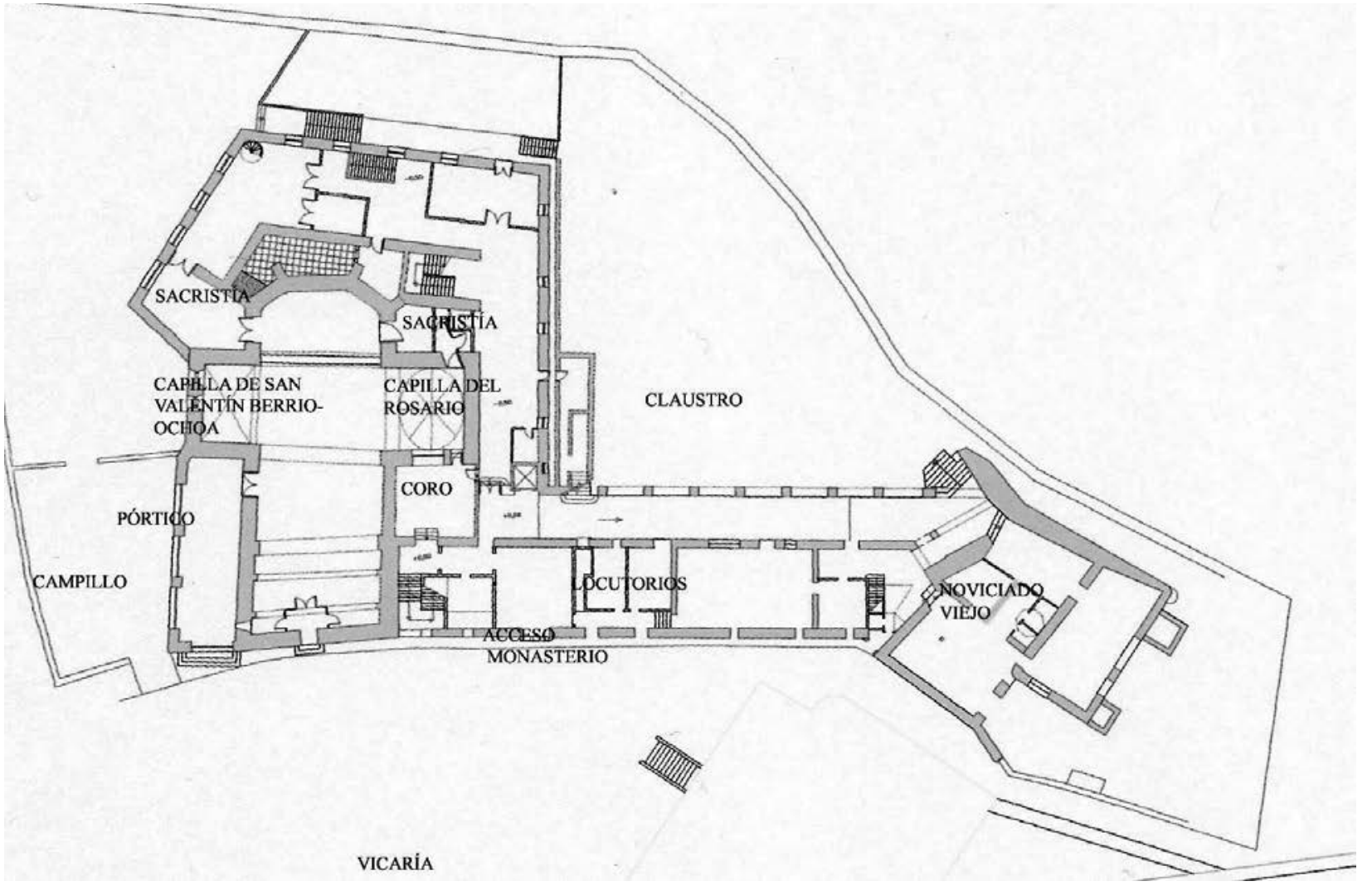

FIGURA 8

Santo Domingo el Real de Madrid. Detalle de altares y capillas. (Autora sobre el plano del Museo Municipal de Madrid. IN. 2695)

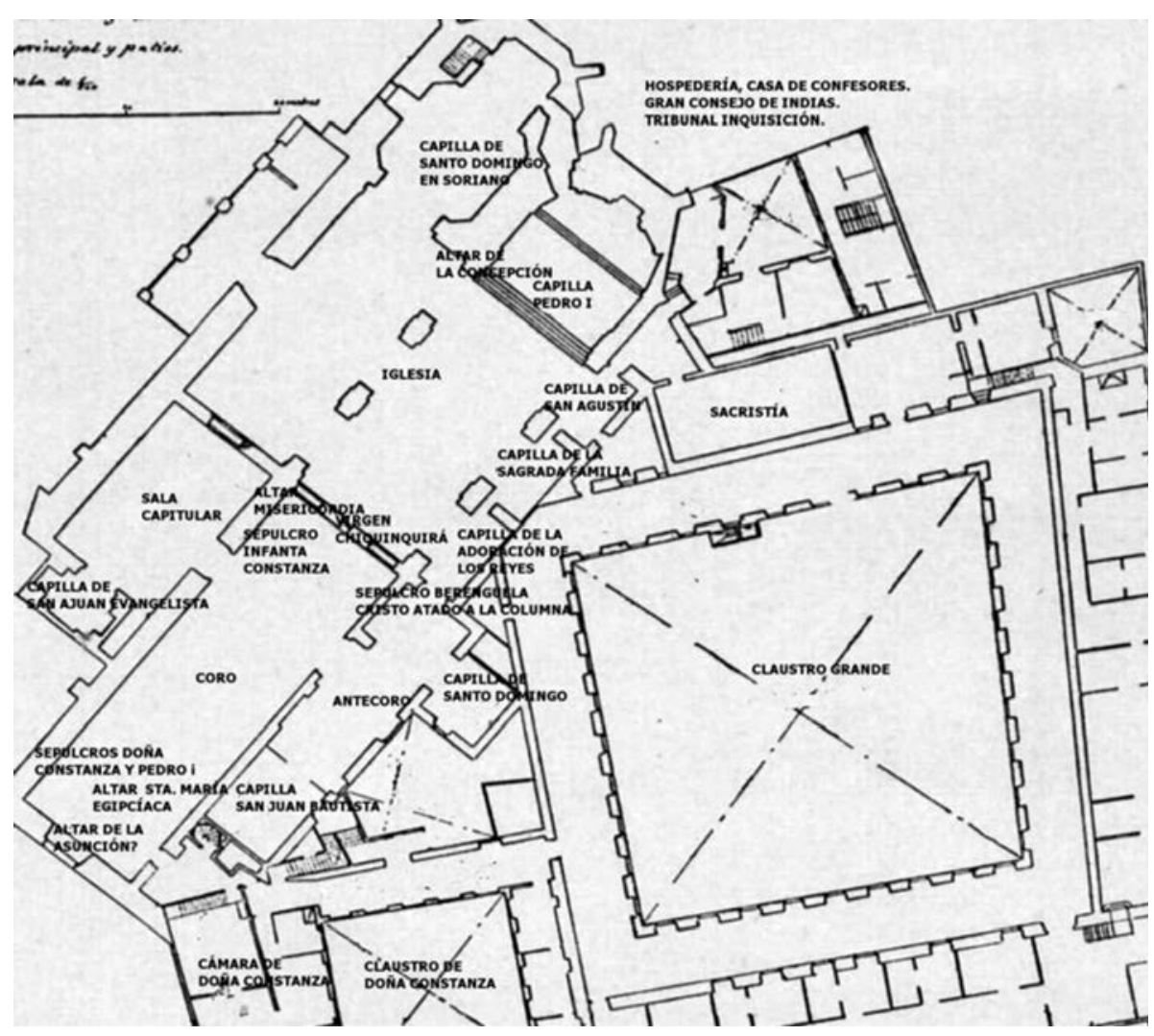


Asimismo, las religiosas del monasterio alsaciano de Unterlinden tenían por costumbre el rezo del Rosario, especialmente en el momento de su muerte, esperando ser recompensadas con una visión de la Virgen que las guiaría a la contemplación de su hijo. ${ }^{84}$

Otra procesión era la que se dirigía el cuarto domingo de cada mes al altar de Santo Domingo y que también se situaba entre la Salve y el 0 lumen, y durante la cual se cantaba el prolijo responsorio $O$ spem miram, el cual era tomado de los maitines del Santo. ${ }^{85}$

Tras el canto de la Salve ante el altar de la Virgen de la Misericordia situado en el coro, las monjas de Santo Domingo el Real de Madrid se dirigían en procesión a la capilla de Santo Domingo, donde cataban O spem Miram. Sin embargo, no resulta claro si esto tenía lugar solo el cuarto domingo de cada mes, como se recoge en el ceremonial dominico, o también otros días, lo cual constituiría un uso particular de este monasterio. ${ }^{86}$ Esta pequeña capilla estaba situada en un pequeño claustro, adyacente a la pared meridional del antecoro, ubicado a su vez en el lado de la Epístola del coro. ${ }^{87}$

Según el relato de Baltasar Quintana, las dominicas caleroganas también celebraban esta procesión el cuarto domingo de cada mes, al menos desde el siglo xvii, aunque es muy probable que se tratase de una costumbre muy anterior. Las monjas subían a una torre adosada a la iglesia monástica de Santa María desde la cual podían ver la pequeña iglesia de Santo Domingo situada al este y, mirando hacia ésta, entonaban $O$ spem miram. ${ }^{88}$ En este caso, siendo precisos, la procesión no se realizaba propiamente al altar de Santo Domingo sino a un lugar desde el cual podía visualizarse este, o mejor dicho, la pequeña iglesia levantada en su honor por el Beato Manés. Sin embargo, teniendo en cuenta que el relato de Quintana es posterior a Trento, y habida cuenta de las implicaciones del concilio en la clausura de las monjas, es probable que, en un principio, la procesión no se dirigiese a la mencionada torre, sino a la iglesia de Santo Domingo, lo que habría implicado una salida de las monjas fuera de la clausura. ${ }^{89}$

a quien se le presentó la Virgen antes de expirar. Frachet. G. de. Vitae Fratrum, en Gelabert, Milagro y Garganta (eds.) 1966: 702-703.

${ }^{84}$ Hamburger 2000: 134

85 Caeremoniale iuxta... 1869: 523. El ya mencionado ceremonial de Potton establecía que «La procesión de Nuestro Padre Santo Domingo se hace, concluidas las Completas, el cuarto Domingo» (Potton 1900: 439).

86 Vidal 1946: 61-64.

87 AGOP, Serie XIV, Liber Q, parte seconda, f. 1007

88 Robles Sierra 1995. La pequeña iglesia dedicada a Santo Domingo constituyó un edificio exento del resto del monasterio hasta finales del siglo $\mathrm{xVI}$, mientras que la mencionada torre permaneció aneja a la iglesia monástica hasta el siglo xVIII (González González 1993: 182).

89 Desde la Alta Edad Media hay constancia documental de las procesiones que se celebraban en monasterios femeninos, tanto en la iglesia como en el claustro o, incluso, fuera del recinto monástico. Se podía acceder a algunas capillas situadas en las proximidades del monasterio para realizar oraciones especiales, por ejemplo en honor de determinados santos (Muschiol 2008: 198).
PRÁCTICAS PENITENCIALES ASOCIADAS A COMPLETAS Y MOVIMIENTOS ULTRARRIGORISTAS EN LOS MONASTERIOS DE DOMINICAS

Además de la complejidad de estas procesiones, completas tuvo también un carácter penitencial desde sus orígenes. Como relata Humberto de Romans, los días festivos, tras esta hora, los frailes recitaban los salmos Miserere o De Profundis mientras que el hebdomadario les administraba las disciplinas con varas de madera sobre sus espaldas desnudas. ${ }^{90}$ Esta costumbre había sido establecida en memoria de Santo Domingo, quien, de acuerdo con el tercero de los Modos de Orar, se mortificaba con una cadena de hierro delante de un Crucifijo. ${ }^{91}$

$\mathrm{Si}$ en el caso de los frailes la penitencia tenía lugar en el coro, las monjas parecen haber dispuesto, al menos en algunos casos, de lugares específicos destinados a tal fin. Como se ha visto, en la última planta de la panda sur del claustro del Moral existía una dependencia de grandes dimensiones en la que las monjas hacían penitencia rezando el Miserere el Viernes Santo delante de una Piedad o una Crucifixión. ${ }^{92}$ Por su parte, las dominicas de San Juan Bautista de Quejana acostumbraban a cantar dicho salmo cada viernes de Cuaresma tras completas. Finalizada esta hora, se dirigían en procesión, probablemente cantando la Salve, a una galería situada a los pies de la capilla de la Virgen del Cabello, en la que cantaban el Miserere y después rezaban, también el Rosario. ${ }^{93}$

Si bien los dominicos dieron suma importancia a la penitencia, los movimientos ultrarrigoristas surgidos en el seno de la Orden durante el proceso de reforma fueron aun más exacerbados, considerando tales mortificaciones un elemento esencial de la vida religiosa. ${ }^{94}$ Entre estos movimientos, el organizado en torno a la Beata de Piedrahita ocupó un lugar destacado. ${ }^{95}$

Sor María de Santo Domingo se caracterizó por el fomento de la austeridad, las mortificaciones, la oración y la experiencia mística asociada a la Pasión, por la profusión

90 Romans 1888-1889, II:131.

91 Tugwell 1958.

92 Ambas imágenes se conservan actualmente en el coro monástico. El crucificado gótico, llamado Cristo de las Aguas, data de mediados del siglo XIV, mientras que la Piedad fue realizada a comienzos de la siguiente centuria (Martínez-Burgos (ed.) 2007: 208, 210 y 218). El salmo Miserere mei domine era uno de los salmos penitenciales escritos por David y, en consecuencia, no solo formaba parte de la liturgia de Semana Santa sino que aparecía por lo tanto en cualquier contexto penitencial o también funerario, y frecuentemente asociado a representaciones de la piedad, como en la Quinta Angustia de Fernando Gallego conservada en el Museo del Prado (Yarza Luaces 1993: 151-152).

93 Martínez Vázquez 1975: 17.

94 Nieva Ocampo 2006a: 52.

95 Beltrán de Heredia -oponiéndose a quienes anteriormente la habían calificado de alumbrada-identificó la espiritualidad de la Beata con aquella propia de los seguidores de Savonarola, quien alcanzó tras su muerte gran predicamento en varios monasterios femeninos italianos, mientras que otros autores, como Hernández Martín y Nieva Ocampo, han acercado el movimiento preconizado por la Beata al espíritu franciscano, por su excesiva austeridad y la preeminencia concedida a la oración (Beltrán de Heredia 1971-1973 [1941]: 529; Hernández Martín 1986; Nieva Ocampo 2006a: 57. Los raptos ascéticos de la Beata de Piedrahita fueron compilados por su confesor fray Diego de Victoria, y publicados hacia 1518 bajo el título de Libro de Oración, que, sin embargo, pasó desapercibido hasta tiempos recientes (Giles 1990). 
de procesiones y bailes místicos y por la ejecución de un canto más largo y solemne que el propio de la liturgia dominica. ${ }^{96}$ Tras profesar como terciaria en Santa Catalina de Piedrahita, se trasladó posteriormente a Santa Catalina de Ávila y -probablemente a causa de los problemas suscitados ya por entonces entre las religiosas abulenses, a causa de su modo de vida-, a una residencia aneja a Santo Tomás. ${ }^{97}$ Previamente, en 1504 , había fundado otra casa de terciarias en la localidad de Aldeanueva. ${ }^{98}$ En 1507 fue enviada a Toledo por orden del provincial Magdaleno, con la finalidad de promover la observancia entre los religiosos y religiosas de la Orden. ${ }^{99}$ No solo esto, sino que se ha apuntado la posibilidad de que visitase también, de camino a Toledo, los monasterios de Segovia y Madrid. ${ }^{100}$

Sin embargo, pese a contar con el apoyo de Cisneros -que debió favorecer la influencia de esta religiosa en su diócesis- y los Reyes Católicos, los excesos de la Beata y sus seguidores despertaron las suspicacias y recelos de los dominicos, quienes dictaron una seria de medidas destinadas a evitarlos en el capítulo Provincial celebrado en Zamora en febrero 1508. Asimismo, el maestro general Tomás de Vío Cayetano remitió una carta a la Provincia por la que prohibía a los frailes tolerar la entrada de la Beata en sus conventos, así como que ésta dictase alguna reforma. ${ }^{101}$ Esto ocasionó gran alboroto y los Reyes Católicos y Cisneros instaron al vicario general de la orden, Tomás Vío Cayetano, a deponer al provincial Diego Magdaleno y a nombrar otro afín a la Beata, haciendo peligrar incluso la unidad de la Provincia, que tantos esfuerzos había costado. Finalmente, tras haberse incoado varios procesos contra sor María, todos ellos malogrados, en 1510 se celebró finalmente uno, con un tribunal absolutamente favorable, que la exoneró de toda culpa, pese a sus heterodoxas y audaces propuestas, presentándola incluso como modelo de virtud. ${ }^{102}$

96 Como muestra de estas prácticas, y en concreto, de estos raptos místicos a partir de la meditación sobre la Pasión de Cristo, sirva de ejemplo el episodio que relató fray Antonio de la Peña, en el proceso que se le hizo a la Beata: "Que estando la dicha soror María in raptu, contemplando y celebrando en sí misma los misterios de la Pasión de Cristo y con los brazos extendidos y puestos en cruz como Cristo fue crucificado, y con el pie derecho puesto sobre el siniestro, algunas veces han probado algunos de le doblar los brazos y de le quitar y apartar un pie de otro y no han podido, como quier que hayan puesto alguna fuerza; y cuando así ella está crucificada, todo el cuerpo juntamente ansí mueven los que prueban lo susodicho como si estoviese enclavada en una cruz» (Sastre Varas 1991: 362).

97 Bilinkoff 1992: 22-23.

98 AHN, Clero, Libros 445, f. 3v; AGOP, Serie XIV, Liber Q, Segunda parte, f. 837.

99 Hernández Martín 1986: 19-28.

100 Bilinkoff 1992: 23; Beltrán de Heredia 1939: 79-80. El caso de Segovia resulta especialmente llamativo dado que no contamos con referencias a la introducción de la reforma, como tampoco a la procedencia de las primeras religiosas, ni parece que -a diferencia de otros- hayan salido de él religiosas destinadas a nuevas fundaciones, o a reformar monasterios existentes.

101 Beltrán de Heredia 1939: 251-253; Hernández Martín 1986: 21 y 23; Nieva Ocampo 2006a: 57; Nieva Ocampo 2006b: 114.

102 Sastre Varas 1990: 364.
FIGURA 9

Santo Domingo el Real de Toledo. Panda meridional del Claustro del Moral. Piso superior destinado a hacer penitencia (AHPT, Fondo Rodríguez.01A-281)

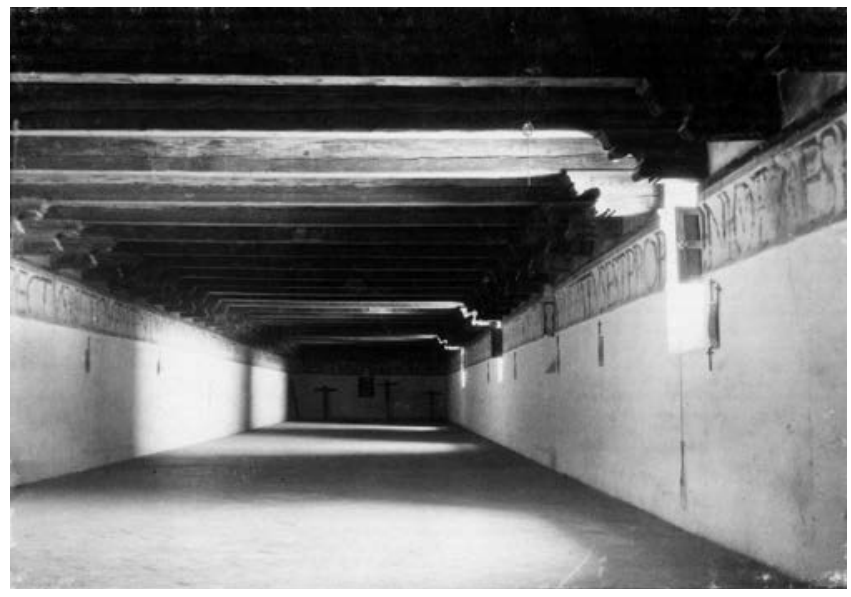

FIGURA 10

Panda meridional y arranques de las pandas oriental y occidental del claustro del Moral con las estaciones decoradas con los Arma Christi.

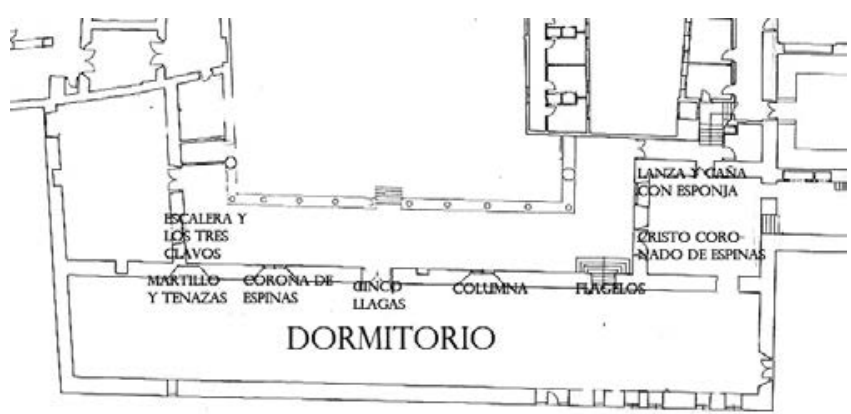

Pese a la relevancia de esta religiosa, hasta la fecha no se ha teniendo en cuenta su más que probable incidencia en la religiosidad, liturgia y, en consecuencia, en el arte y arquitectura de los monasterios fundados o reformados por ella. Lamentablemente, no hemos conservados libros litúrgicos procedentes de los beaterios de Piedrahita, Ávila y Aldeanueva, ni tampoco los edificios, con excepción de algunas ruinas. Sin embargo, determinadas características del mencionado monasterio de Santo Domingo el Real de Toledo $y$, en concreto, de la panda meridional del claustro del Moral, parecen apuntar a una posible influencia de la Beata en la liturgia y arquitectura del monasterio. ${ }^{103}$ Tales características fueron la mencionada sala del último piso destinada a prácticas penitenciales, la descrita complejidad de la liturgia procesional, la decoración tanto de las ventanas como de las puertas de esta panda con los Arma Christi y las Cinco Llagas y la presencia de una tabla -hoy desaparecida- representando el Santo Entierro en el luneto situado sobre la puerta que daba acceso a la dependencia situada entre este claustro y el coro monástico. Por lo tanto, además de servir de escenario a la compleja liturgia procesional de completas, esta panda

\footnotetext{
103 Pérez Vidal 2012.
} 
parece haber tenido un destacado uso penitencial, ligado a la conmemoración de la Pasión de Cristo, la cual, como se ha visto, ocupó un lugar destacado en la oración y religiosidad de la Beata, que conducía al éxtasis místico.

Más aún, la hipótesis de la influencia de la Beata en la arquitectura de esta panda viene apoyada por las fuentes documentales, ya que, como se ha mencionado, las obras de reconstrucción de este claustro se iniciaron en abril de 1507, pasados doce años de la supuesta reforma de este monasterio, y coincidiendo con la venida de sor María de Santo Domingo a Toledo. Asimismo, la interrupción de las obras en abril de 1508 coincidió con el veto a la labor reformadora de esta religiosa, por parte del maestro general. ${ }^{104}$

\section{CONCLUSIONES}

Mientras que el desarrollo de la liturgia procesional de completas en los conventos masculinos de la Orden de Predicadores es bien conocido, su celebración en los monasterios femeninos no había atraído hasta la fecha la atención ni de los liturgistas, ni de los historiadores. Esto se encuadra dentro de la generalizada desconsideración de la liturgia de las monjas dominicas, a la cual, debido al aparente vacío legislativo al respecto, al que se suma la desaparición de gran cantidad de libros litúrgicos de cronología medieval, se le ha negado un carácter propio.

Sin embargo, como se ha visto, un estudio conjunto de la arquitectura, los escasos fragmentos litúrgicos conservados y otras fuentes documentales no litúrgicas permite reconstruir, al menos en parte, algunos de los aspectos de esta liturgia extinta. Asimismo, se pone de manifiesto el papel activo de algunas mujeres -monjas, beatas y laicas-en su configuración $y$, en consecuencia, las diferencias y las peculiaridades de las celebraciones en cada monasterio, reflejo en buena medida de la incidencia del contexto religioso local.

Los comentados ejemplos de los monasterios de Madrid, Toledo, Caleruega y Lekeitio evidencian como, con frecuencia, las procesiones tras completas no se desarrollaron en la iglesia o coro, sino que discurrieron por el claustro, con sus capillas o estaciones litúrgicas, por otras dependencias, o incluso, en algunos casos, fuera de los muros de la clausura.

El desarrollo de las procesiones de completas por el claustro, o claustros, se documenta también en otros monasterios femeninos pertenecientes a distintas órdenes monásticas, especialmente entre las cistercienses. Este fue el caso de Santa María Real de las Huelgas de Burgos. Así lo demuestran los restos de yeserías conservadas en el pasaje entre el claustro de San Fernando y las Claustrillas, que contienen una inscripción en la que se contiene un extracto de la Salve. ${ }^{105}$ Pese a la tremenda deuda de los dominicos con el Cister, la influencia, según lo mencionado líneas arriba, parece haber sido en este caso a la inversa.

104 AMSDRT, Docs. 360, 361 y 681; Ibídem, Libro Becerro de 1507, Sig 3.134, f 342

105 A partir de los epígrafes existentes en el locutorio y el paso de claustro de San Fernando a las Claustrillas, de la liturgia procesional cisterciense, y del estudio comparativo con otros monasterios, Carrero Santamaría ha reinterpretado las Claustrillas como patio de la enfermería y del palacio abacial, la capilla de la Asunción, como oratorio inicial y posterior capilla de la enfermería, y la capilla de Santiago una capilla cementerial (Carrero Santamaría 2004: 713 y 2014).
La celebración de completas en Santo Domingo el Real de Toledo fue paradigmática de la complejidad litúrgica de esta hora del oficio. Las procesiones tuvieron por escenario la panda meridional del claustro principal, en el que un grupo de altares sirvieron de estaciones litúrgicas. De acuerdo con sus características arquitectónicas, y teniendo en cuenta las documentadas fechas de su construcción, podemos relacionar con bastante probabilidad la reconstrucción de este claustro con la influencia de la Beata de Piedrahita, quedando interrumpida tal obra cuando la Orden prohibió la actividad reformadora de esta religiosa.

Aunque desconocemos cuándo se abandonó el uso procesional de esta panda, este no debió prolongarse en cualquier caso más allá de Trento. En efecto, este debió quedar en desuso tras la construcción de un nuevo claustro al norte de la iglesia monástica a partir de 1583, consecuencia, sin duda, de la aplicación de los decretos tridentinos a través de sínodo toledano de $1582 .{ }^{106}$

\section{BibliografíA}

Alonso Getino, L. G. 1925. Origen del Rosario y Leyendas castellanas del siglo XIII sobre Sto. Domingo de Guzmán. Vergara: El Santísimo Rosario.

Alvarenga, P. 1992. "A Música também é escrita», en M. V Sul Mendes (ed), Tesouros da Biblioteca Nacional: 253-284. Lisboa: INAPA.

Álvarez Díaz, C. 2004. "Espiritualidad y monacato femenino en las Cantigas de Santa María», en F. J. Campos y Fernández de Sevilla (coord.), La clausura femenina en España. Actas del Simposium (I): 141-166. San Lorenzo de El Escorial: Instituto Escurialense de Investigaciones Históricas y Artísticas.

Ancelet-Hustache, J. 1930. «Les Vitae sororum d'Unterlinden. Édition critique du manuscrit 508 de la bibliothèque de Colmar». Archives d'histoire doctrinale et littéraire du Moyen Âge 5: 317-513.

Andrés, G. de 1989. "La colección de códices del convento de Santo Tomás de Ávila en la Biblioteca Nacional. Su identificación». Hispania Sacra 41, 83: 105-128.

Arbeteta Mira, L. 1996. Vida y arte en las clausuras madrileñas. El ciclo de la Navidad. Madrid: Museo Municipal de Madrid.

Asensio Palacios, J. C.; Biain, M. S. y Salvador Bermejo, A. 2007. "La música en la Orden de Predicadores», en P. Martínez-Burgos (ed.), Dominicas VIII Centenario: 92-106. Toledo: Empresa pública «Don Quijote de la Mancha 2005, S.A.».

Badano, S. 2010. "I fondi archivistici», en C. Cavelli Traverso (coord.), Monache domenicane a Genova: 159-168. Roma: De Luca Editori d`arte.

Barrado Barquilla, J. 1985. «El convento de San Pedro Mártir». Notas históricas en el V Centenario de su imprenta (1483-1983). Toletum 18: 181-211.

Baury, G. 2010. "Une bibliothèque médiévale de moniales cisterciennes en Castille. Cañas et les membra disjecta de son missel». Cîteaux. Commentarii cistercienses 61/2-4: 141-183.

Beltrán de Heredia, V. 1939. Historia de la Reforma de la Provincia de España (1450-1550). Roma: Istituto Histórico Domenicano.

Beltrán de Heredia, V. 1971-1973 [1941]. «Las corrientes de espiritualidad entre los dominicos de Castilla durante la primera mitad del siglo XVI», en Miscelánea Beltrán de Heredia: Colección de artículos sobre historia de la teología española, III: 519-672. Salamanca: OPE.

106 El claustro fue proyectado en 1583 por Diego de Alcántara, discípulo colaborador de Juan de Herrera, maestro mayor de la Catedral y activo en Toledo entre 1571 y 1586 (Martínez Caviró 2005: 57; Marías Franco 1983, Tomo I: 175-176). Sobre el sínodo de Toledo de 1582 véase Rodríguez G. de Ceballos 1991: 45. 
Berceo, G. de 1997. Milagros de Nuestra Señora, F. Baños Vallejo (ed.) Barcelona: Francisco Rico y Editorial crítica.

Berger, T. M. 2011. Gender Differences and the Making of Liturgical Tradition: Lifting a Veil on Liturgy's Past. Liturgy, Worship and Society Series. Burlington: Ashgate.

Berger, T. M y Gerhards, A. (eds.) 1990. Liturgie und Frauenfrage: Ein Beitrag zur Frauenforschung aus liturgiewissenschaftlicher Sicht. Pietas liturgica 7. St. Ottilien: EOS Verlag.

Bilinkoff, Jodi. 1992. "A Spanish Prophetess and Her Patrons: The Case of María de Santo Domingo». Sixteenth Century Journal 23: 21-34.

Bonniwell, W. R. 1945. A history of the Dominican Liturgy (1215-1945). New York: Joseph F. Wagner.

Boyle, L. E. y Gy. P. M. (dirs.) 2004. Aux Origines de la Liturgie Dominicaine: Le Manuscrit Santa Sabina XIV L1. París y Roma: École française de Rome y CNRS éditions.

Caeremoniale iuxta ritum sacri orinidis praedicatorum. 1869. Ed. por A. V. Jandel. Malinas: H. Decian.

Calvo Alonso, I. 2011. "Catálogo de los cantorales del siglo xvi del convento de San Esteban de Salamanca». Archivo Dominicano XXXII: 295-394.

Canal Sánchez-Pagín, J. M. 1963. Salve Regina misericordiae: Historia y leyendas en torno a esta antífona. Roma: Edizioni di storia e letteratura.

Cannon, J. 2013. Visual Riches. Art in the Dominican Churches of Central Italy in the Thirteenth and Fourteenth Centuries. New Haven and London: Yale University Press.

Cantimpré, T. de 1895. Bonum universale de apibus quid illustrandis saeculi decimi tertii moribus conferat, E. Berger (ed.). París: Apud Thorin filiumque bibliopolas.

Carrero Santamaría, E. 2004. «Observaciones sobre la topografía sacra y cementerial de Santa María la Real de las Huelgas, en Burgos, y su materialización arquitectónica», en F. J. Campos y Fernández de Sevilla (coord.), La clausura femenina en España. Actas del Simposium (I): 695-716. San Lorenzo de El Escorial: Instituto Escurialense de Investigaciones Históricas y Artísticas.

Carrero Santamaría, E. 2014. «Epigrafía y liturgia estacional entre el locutorio y el pasaje a la enfermería de la abadía de Santa María la Real de las Huelgas de Burgos». Territorio, Sociedad y Poder 9: 115-132.

Carroll, J. 2012. «Subversive Obedience: Images of Spiritual Reform by and for $15^{\text {th }}$ century nuns», en T. Martin (ed.), Reassessing the Roles of Women as Makers of Medieval art and architecture: 703737. Leiden: Brill.

Castilla, C. 1998. Libro de devociones y oficios, C. L. Wilkins (ed.). Exeter: University of Exeter Press.

Clark, A. 2002. "The Priesthood of the Virgin Mary: Gender Trouble in the Twelfth Century». Journal of Feminist Studies in Religion CXVIII/1: 5-24.

Coli, M. 2009. La cronaca del monastero domenicano di San Giorgio di Lucca. Pisa: Edizioni ETS.

Constitutiones et Acta Ordinis Fratrum Praedicatorum: 1232-2001. 2002. Digitale Bibliothek Spezial. Berlin: Directmedia Publishing e Istituto Storico Domenicano.

Conway, M. 1999. The Diario of the Printing Press of San Jacopo di Ripoli, 1476-1484: Commentary and Transcription. Storia della Tipografía e del Commercio Librario 4. Florence: Olschki.

Creytens, R. 1948. «Les Constitutions des Frères Prêcheurs dans la redaction de S. Raymond de Peñafort (1241)». Archivum Fratrum Praedicatorum 18: 5-68.

Denifle, H. 1885. "Die Constitutionen des Predigerordens von Jahre 1228». Archiv für Literatur-und Kirchengeschichte des Mittelalters 1: $165-227$.

Dirks, A. 1979. «De Tribus libris manu scriptis primaevae liturgiae Dominicanae». Archivum Fratrum Praedicatorum 49: 5-37.

Español Beltrán, F. 2002-2003. «El salterio y libro de horas de Alfonso el Magnánimo y el cardenal Joan de Casanova». Locvs Amoenvs 6: 91-114.

Fassler, M. 2004. "Music and the Miraculous: Mary in the MidThirteenth-Century Dominican Sequence Repertory», en L. E.
Boyle y P. M. Gy (dirs.), Aux Origines de la Liturgie Dominicaine: Le Manuscrit Santa Sabina XIV L1: 229-278. París y Roma: École française de Rome y CNRS éditions.

Frazão, M. L. Mendes André Coelho 1998. Iluminura Renascentista do Convento de Nossa Senhora do Paraíso de Évora. Livros do coro, 136, 137, 138 e 139. Tese de Mestrado em Historia da Arte. Lisboa: Universidade de Lisboa, Faculdade de Letras, 2 vols.

Fueyo Suárez, B. 2007. "El exemplar de la liturgia dominica de Salamanca». Archivo Dominicano 28: 81-118. [Reed. en Fueyo Suárez, B. 2012. Liturgia y culto en San Esteban de Salamanca: 15-51. Salamanca: San Esteban Editorial].

Fueyo Suárez, B. 2008. "El Breviarium Portatile (ss. XIV-XV) de Santo Domingo el Real de Toledo», Toletana. Cuestiones de Teología e Historia 19: 161-188.

Fueyo Suárez, B. 2009a. «Bloque primitivo del Breviario 06/ 508 de Santo Domingo el Real de Toledo». Archivo Dominicano 30: 103-144.

Fueyo Suárez, B. 2009b. «El Breviarium Portatile (s XIV-XV) de Santo Domingo el Real de Toledo». Ciencia Tomista 136: 363-398.

Fueyo Suárez, B. 2011. «Procesionales impresos en España del rito dominicano (ss. xv-xvi)», Ciencia Tomista 138, no 444: 151-212. [Reed. en Fueyo Suárez, B. 2012. Liturgia y culto en San Esteban de Salamanca: 85-122. Salamanca: San Esteban].

Fueyo Suárez, B. 2012. Liturgia y culto en San Esteban de Salamanca. Salamanca: San Esteban Editorial.

Galán Vera, M. J. 2007. "Los libros de Santo Domingo el Real», en P. Martínez-Burgos García (ed.), Dominicas VIII Centenario: 70-89. Toledo: Empresa pública «Don Quijote de la Mancha 2005, S.A.».

Galán Vera, M. J. 2010. "Cristo de las aguas, Cristo de Antequera y Cristo Redentor, en Santo Domingo el Real de Toledo», en F. J. Campos y Fernández de Sevilla (ed.), Los crucificados, religiosidad, cofradías y arte: Actas del Simposium 3/6-IX-2010: 755-770. San Lorenzo de El Escorial: Instituto Escurialense de Investigaciones Históricas y Artísticas.

Galán Vera, M. J.; Martínez Gil, C. y Peñas Serrano, P. 2005. «La música en los conventos dominicos de Toledo (siglos XVI-XVIII)». Anales Toledanos 41: 255-316.

Galmés, L. y Gómez, V. T. (eds.) 1987. Santo Domingo de Guzmán. Fuentes para su conocimiento. Madrid: Biblioteca de Autores Cristianos.

Gelabert, M.; Milagro, J. M. y Garganta, J. M. 1966. Santo Domingo de Guzmán visto pos sus contemporáneos. Madrid: Biblioteca de Autores Cristianos.

Gilardi, C. 2004. "Ecclesia Laicorum e Ecclesia Fratrum. Luoghi e oggetti per il culto e la predicazione secondo I'Ecclesiasticum Officium dei frati predicatori», en L. E. Boyle y P-M. Gy (dirs.), Aux Origines de la Liturgie Dominicaine: Le Manuscrit Santa Sabina XIV L1: 379-443. París y Roma: École française de Rome y CNRS éditions.

Gilardi, C. 2006. «Liturgia, cerimoniale e architettura secondo \Ecclesiasticum Officium dei Fratri predicatori», en F. Cervini y C. E. Spantigati (eds.), II tempo di Pio V, Pio V nel tempo:atti del convegno internazionale di studi, Bosco Marengo, Alessandria, 11-13 marzo 2004:1-77. Alessandria: Edizioni dell'Orso.

Giles, M. E. 1990. The Book of Prayer of Sor María of Santo Domingo. A Study and Translation. Albany: State University of New York Press.

Gleenson, P. 1972. «Dominican liturgical manuscripts from before 1254», Archivum Fratrum Praedicatorum 42: 81-135.

Gleenson, P. 2004. "The Pre-Humbertian sources revisited», en L. E. Boyle y P. M. Gy (dirs.), Aux Origines de la Liturgie Dominicaine: Le Manuscrit Santa Sabina XIV L1: 99-114. Paris y Roma: École française de Rome y CNRS éditions.

González Fuente, A. 1981. La vida litúrgica en la Orden de Predicadores. Estudio en su legislaciòn: 1216-1980. Roma: Institutum historicum FF. Praedicatorum.

González Fuente, A. 2003. «El procesionario O.P. del año 1609». Archivo Dominicano 24: 21-32.

González González, C. 1993. Real Monasterio de Santo Domingo de Caleruega. Fundación de Alfonso X El Sabio. Salamanca: Editorial San Esteban. 
Gorton, F. Jr. 1949. Compline in the Dominican rite: 1256 to 1949 Thesis PhD. University of Indiana.

Guerrini. F. M. (ed.) 1921. Ordinarium iuxta ritum Sacri Ordinis fratum praedicatorum, 1256. Roma: Società tipografica A. Manuzio.

Hamburger, J. F. 1997. Nuns as Artists: The Visual Culture of a Medieval Convent. Berkeley: University of California Press.

Hamburger, J. F. 2000. "Offices des Morts et Processionnaux selon l'usage des dominicains», en M. Blondel, J. F. Hamburger y C. Leroy (comisarios), Les dominicaines d'Unterlinden, Exposition, Musée de Unterlinden, Colmar, 10 de décembre 2000-10 juin 2001, II: 78-79. Paris: Somogy, éditions d’art.

Hernández Martín, R. 1980. «Actas de la congregación de la Reforma de la Provincia de España (I)». Archivo Dominicano 1: 7-140.

Hernández Martín, R. 1981. «Actas de la Congregación de la Reforma de la Provincia de España (y II)». Archivo Dominicano 2: 5-118.

Hernández Martín, R. 1986. «Actas de los Capítulos Provinciales de la Provincia de España del siglo XVI (II)». Archivo Dominicano 7: 5-47.

Horst, U. 2009. Dogma und Theologie. Dominikanertheologen in den Kontroversen um die "Immaculata Conceptio». Berlin: Akademie Verlag (Quellen und Forschungen zur Geschichte des Dominikanerordens. N.F. 16).

Huglo, M. 1967. «Règlement du XIII siècle pour la trascriptión des livres notés», en M. Ruhnke (ed.), Festschrift Bruno Stäblein zum 70, Geburstag: 121-133. Kassel: Bärenreiter.

Huglo, M. 1990. "Les processionnaux de Poissy», en P. Clerck y É Palazzo (eds.), Rituels: mélanges offerts à Pierre-Marie Gy: 339346. Paris: Editions du Cerf.

Huglo, M. 1999. Les manuscrits du Processional, Volume I, Autriche à Espagne. Repertoire internacional des sources musicales B XIV(1). Munich: Henle.

Jäggi, C. 2000. «Architecture et disposition liturgique des couvents féminis dans le Rhin supérieur aux $X I^{e}{ }^{e}$ et $X I V^{e}$ siècles», en $M$ Blondel, J. F. Hamburger y C. Leroy (comisarios), Les dominicaines d'Unterlinden, Exposition, Musée de Unterlinden, Colmar, 10 de décembre 2000-10 juin 2001, I: 89-107. Paris: Somogy, éditions d’art.

Jäggi, C. 2001. «Eastern Choir or Western Gallery? The Problem of the Place of the Nuns ' Choir in Königsfelden and other Early Mendicant Nunneries». Gesta XI/1: 79-93.

Jäggi, C. 2002. «Liturgie und Raum in franziskanischen Doppelklöstern. Königs-felden und S. Chiara Neapel im Vergleich», en N. Bock (ed.), Art, Cérémonial et Liturgie au moyen Âge, Actes du 3 er cycle Romand des Lettres, 24-25 mars, 14-15 avril, 12-13 mai 2000: 223246. Roma: Viella.

Jäggi, C. 2006. Frauenklöster im Spätmittelalter: Die Kirchen der Klarissen und Dominikanerinnen im 13. und 14. Jahrhundert. Petersberg:Michael Imhof Verlag.

Jäggi, C y Lobbedey, U. 2008. «Church and cloister. The Architecture of female monasticism in the Middle Ages», en J. F. Hamburger y S. Marti (eds.), Crown and veil: Female Monasticism from the Fifth to the Fiftheenth Centuries: 109-131. New York: Columbia University Press.

Labarga García, F. 2003. «La devoción del Rosario: datos para su historia». Archivo Dominicano 24: 225-277.

Lewis, G. J. 1996. By Women, for Women, about Women: The SisterBooks of Fourteenth-Century Germany. Toronto: Pontifical Institute of Mediaeval Studies.

Lippini, P. 2008 [1990]. La vita quotidiana di un convento medievale. Gli ambiente, le regole, l'orari e le mansioni dei Fratri domenicani del tredicesimo secolo. Bologna: Edizioni Studio Domenicano

López, J. [1613] 2003. Tercera parte de la historia general de Sancto Domingo y de su Orden de Predicadores. Valladolid: Maxtor.

Macy, G. 2000. "The Ordination of Women in the Early Middle Ages». Theological Studies 61: 481-507.

Macy, G. 2008. The Hidden History of Women's Ordination. Female Clergy in the Medieval West. Oxford: Oxford University Press.

Marías Franco, F. 1983. La arquitectura del Renacimiento en Toledo (1541-1631). Madrid: IPIET.
Martínez Caviró, B. 2005. «El arte en el monasterio toledano de Santo Domingo el Real. Los monasterios de Madre de Dios y de Jesús y María», en P. Martínez-Burgos (ed.), Dominicas VIII Centenario: 42-67. Toledo: Empresa pública «Don Quijote de la Mancha 2005, S.A.».

Martínez Vázquez, F. 1975. Reseña histórica y Catálogo documental del Monasterio de Quejana (1374-1974). Vitoria: Obra cultural de la Caja de Ahorros de la ciudad de Vitoria.

Medrano, M. 1734. Historia de la Provincia de España de la Orden de Predicadores. Madrid: Imprenta de Alfonso de Mora.

Migne, J. P. (ed.) 1890. Patrologia Latina. París: Garnier Fratres, Editores et. J. P. Migne successores

Moiteiro, G. Corralejo 2013. As dominicanas de Aveiro (c. 1450-1525): Memória e identidade de uma comunidade textual. Tese de Doutoramento em Historia, Universidade Nova de Lisboa.

Moreton, M. 2013. 'Scritto di Bellissima Lettera': Nuns' Book Production in Fifteenth and Sixteenth-century Italy. Ph dissertation, lowa University.

Muñoz Fernández, A. 1990. «Fiestas laicas y fiestas profanas en el Madrid medieval. Un primer acercamiento al tema», en El Madrid medieval: sus tierras y sus hombres: 151-175 Madrid: Asociación Cultural Al-Mudayna.

Muschiol, G. 1994. Famula dei: zur Liturgie in merowingischen Frauenklöstern. Münster: Aschendorff Verlag.

Muschiol. G. 2001. «Liturgie und Klausur. Zu den liturgischen Voraussetzungen von Nonnenchören», en I. Crusius (ed.), Studien zum Kanonissenstifte: 129-148. Göttigen: Studien zu Germani Sacra-Veröffentlichungen des Max-Planck-Instituts für Geschichte.

Muschiol. G. 2003. «Architektur, Funktion und Geschlecht: Westfälische Klosterkirchen des Mittelalters». Westfälisches Klosterbuch 3: 791-811.

Muschiol, G. 2008. "Time and Space: Liturgy and Rite in Female Monasteries of the Middle Ages», en J. F. Hamburger y S. Marti (eds.), Crown and Veil: Female Monasticism from the Fifth to the Fifteenth Centuries: 191-206. New York: Columbia University Press.

Muschiol. G. 2010. «Osterliturgie in Frauenklöstern des Mittelalters», en L. M. Koldau (coord.), Passion und Ostern in den Lüneburger Klöstern: 45-66. Kongressbericht Ebstorf: Verlag Kloster Ebstorf.

Muschiol. G. 2012. «Migrating Nuns-Migrating Liturgy? The Context of Reform in Female Convents of the Late Middle Ages», en T. M. Berger (ed.), Liturgy in Migration: Cultural Contexts from the Upper Room to Cybserpsace: 83-100. Minnesota: Liturgical Press

Muschiol. G. 2013. "Fromme-Frauen" und ihr Anteil an der Liturgie in Kloster und Stiftskirchen. Haus am Dom de Mainz.

Naughton, J. 1998. «Books for a Dominican Nun's Choir: Illustrated Liturgical Manuscripts at Saint-Louis de Poissy, c. 1330-1350», en M. Manion y B. Muir, The Art of the Book. Its Place in Medieval Worship: 67-109. Exeter: University of Exeter Press.

Naughton, J. 1999-2000. «From Unillustrated Book to Illustrated Book: Personalization and Change in the Poissy Processional». Manuscripta 43/44: 161-187.

Nieva Ocampo, G. 2006a. «Incorporarse a Jesucristo: prácticas sacramentales y penitenciales entre los dominicos castellanos en el siglo XVI». Hispania Sacra 58-117: 39-67.

Nieva Ocampo, G. 2006b. «La creación de la Observancia regular en el convento de San Esteban de Salamanca durante el reinado de los Reyes Católicos». Cuadernos de Historia de España 80: 91-126.

Noakes, S. 1991. "The Development of the Book-market in Late Quattrocento Italia: Printers Failures and the Role of the Middle man». Journal of Medieval and Renaissance Studies 11: 23-55.

Pérez Vidal, M. 2012. «Observancia y rigorismo. Consecuencias de la reforma de la Orden de Predicadores y de algunos movimientos rigoristas en la liturgia y arquitectura de los monasterios de dominicas de la "Provincia de España», en N. Fernández Rodríguez y M. Fernández Ferreiro (eds.), Literatura medieval y renacentista en España: líneas y pautas. Actas del III Congreso internacional de la SEMYR, Celebrado en Oviedo del 27 al 30 de septiembre de 2010: 799-810. Salamanca: SEMYR.

Potton, A. M. 1900. Ceremonial para uso de las religiosas dominicas, Traducido al castellano y acomodado a las costumbres de España 
por el Reverendo Padre Fray Perfecto Canteli, O.P. Vergara: El Santísimo Rosario.

Quintana, J. de 1629. A la muy antigua, noble y coronada villa de Madrid: historia de su antigüedad, nobleza y grandeza. Madrid: Imprenta del Reyno.

Rieland, E. M. 1945. De Completorio Fratrum Praedicatorum Ephemerides Liturgicae, Vols. 59 y 60. Rome: Edizioni liturgiche

Roberts, A. 2008. Dominican Women and Renaissance Art, The Convent of San Domenico of Pisa. Cornwall: Ashgate Publishing Limited.

Robles Sierra, A. 1995. «El P. Baltasar de Quintana y su información sobre Caleruega», en C. Aniz Iriarte y L. V. Díaz Martín (coord.), Santo Domingo de Caleruega. Contexto Cultural III Jornadas de Estudios Medievales: 361-380. Salamanca: Editorial San Esteban.

Rodríguez G. de Ceballos, A. 1991. «Liturgia y configuración del espacio en la arquitectura española y portuguesa a raíz del Concilio de Trento». Anuario del Departamento de Historia y Teoría del Arte 3: 43-52.

Rodríguez y Fernández, I. 1903. Historia de la muy noble y muy leal y coronada villa de Medina del Campo: conforme a varios documentos y notas a ella pertinentes. Madrid: Imp. de San Francisco de Sales Madrid.

Romans, H. 1888-1889. Opera de Vita Regulari, J. J. Berthier (ed.). Roma: Befani.

Roncroffi, S. 2009. Psallite Sapienter. Codici Musicali delle Domenicane Bolognesi. Florence: Olschki.

Rucquoi, A. 2012. «Autores mendicantes en la cultura hispánica (siglos XIII-XV)». Cuadernos de Historia de España 85-86: 621-643.

Russo, D. 1996. «Les représentations mariales dans l’art d’Occident. Essai sur la formation d’une tradition iconographique», en D. logna-Prat; Ë. Palazzo y D. Russo (eds.), Marie. Le culte de la Vierge dans la société médiévale: 174-291. Paris: Beauchesne.

Sánchez Hernández, L. 1994. Patronato regio y órdenes religiosas femeninas en el Madrid de los Austrias: Descalzas Reales, Encarnación y Santa Isabel. Madrid: Universidad Complutense.

Sastre Varas, L. 1990. «Proceso de la Beata de Piedrahita (I)». Archivo Dominicano 11: 359-402.

Sastre Varas, L. 1991. "Proceso de la beata de Piedrahita (II)». Archivo Dominicano 12: 337-386.

Sauer, C. 2007. «Zwischen Kloster und Welt: Illuminerte Handschrifen aus dem Dominikanerinnenkonvent St. Katharina in Nürnberg», en C. Jäggi, S. Marti y H. Röckelein (eds.), Frauen-Kloster-Kunst. Neue
Forschungen zur Kulturgeschichte des Mittelalters, Internationales Kolloquium im Zusammenhang mit Krone und Schleier: Kunst aus mittelalterlichen Frauenklöstern: 113-129. Die Wolfsburg, Mülheim/Ruhr; Turnhout: Brepols.

Sierra Corella, A. 1935. "Santo Domingo el Real de Toledo. Noticias sobre su fundación y suerte». Revista española de arte IV, 7: 304-308.

Thomas, A. H. 1965. De oudste constituties van de Dominicanen: Voorgeschiedenis, tekst, bronnen, ontstaan en ontwikkeling (1215-1237). Leuven: Bibliothèque de la Revue d'histoire ecclésiastique.

Thomas, A. H. 1969. «La profession religieuse des Dominicains: formule, cérémonies, histoire». Archivum Fratrum Praedicatorum 39: 5-52.

Tozzi, I. 2011. «I codici minaiti della Domenicana suor Eufrasia Burlamacchi al tramonto dell' età medievale». Pecia 14: 95-105.

Tugwell, S. 1958. «The Nine ways of Prayer of Saint Dominic, A Textual and Critical Edition», Mediaeval Studies 47: 94-103.

Tugwell, S. 1993. «Humbert de Romans». Mémoire dominicaine 2: 21-32.

Verwilst, L. 1933. "Les Complies Dominicaines». Analecta Ordinis Praedicatorum 41: 267-280.

Vidal, C. de J. 1946. Breve reseña histórica del convento de Santo Domingo el Real de Madrid, desde su fundación por el mismo Santo Patriarca, año del Señor de 1218. Santiago de Compostela: Librería del Seminario Conciliar.

Walz, A. M. 1967. «Die 'Miracula beati Dominici' der Beata Cecilia». Archivum Fratrum Praedicatorum 37: 5-45.

Wilkins, C. L. 1998. «El devocionario de Sor Constanza: otra voz femenina medieval», en Actas del XII Congreso de la Asociación Internacional de Hispanistas, Birmingham, 21-26 de Agosto de 1995: 340-349. University of Birmingham: Doelphin Books.

Winston-Allen, A. 2004. Convent Chronicles. Women Writing about Women and Reform in the Late Middle Ages. University Park: Pennsylvania State University Press.

Yarza Luaces, J. 1993. Los Reyes Católicos: paisaje artístico de una monarquía. Madrid: Nerea.

Zanovello, Giovanni. 2009. «In oratorio nemo aliquidi agat': Savonarola, lo spazio sacro e la musica», en M. J. Blozam, G. Filocamo y L. Holford-Stevens (eds.), In Uno gentile et subtile ingenio: Studies in Renaissance Music in Honour of Bonnie J. Blackburn: 129-136. C.E.S.R., Collection «Epitome Musical. Turnhout: Brepols. 